\title{
Phylogeography of the marbled crab Pachygrapsus marmoratus (Decapoda, Grapsidae) along part of the African Mediterranean coast reveals genetic homogeneity across the Siculo-Tunisian Strait versus heterogeneity across the Gibraltar Strait
}

Temim Deli, Sara Fratini, Lapo Ragionieri, Khaled Said, Noureddine Chatti \& Christoph D. Schubart

To cite this article: Temim Deli, Sara Fratini, Lapo Ragionieri, Khaled Said, Noureddine Chatti \& Christoph D. Schubart (2016) Phylogeography of the marbled crab Pachygrapsus marmoratus (Decapoda, Grapsidae) along part of the African Mediterranean coast reveals genetic homogeneity across the Siculo-Tunisian Strait versus heterogeneity across the Gibraltar Strait, Marine Biology Research, 12:5, 471-487, DOI: 10.1080/17451000.2016.1154972

To link to this article: http://dx.doi.org/10.1080/17451000.2016.1154972

冓 Published online: 27 May 2016.

III Article views: 47
Submit your article to this journal 지

\section{View Crossmark data $₫$}




\title{
Phylogeography of the marbled crab Pachygrapsus marmoratus (Decapoda, Grapsidae) along part of the African Mediterranean coast reveals genetic homogeneity across the Siculo-Tunisian Strait versus heterogeneity across the Gibraltar Strait
}

\author{
Temim Deli ${ }^{a}$, Sara Fratini ${ }^{b}$, Lapo Ragionieri ${ }^{b, c}, K$ Khaled Said ${ }^{a}$, Noureddine Chatti ${ }^{a}$ and Christoph D. Schubart ${ }^{d}$ \\ aLaboratory of Genetics, Biodiversity and Enhancement of Bioresources, University of Monastir, Higher Institute of Biotechnology of

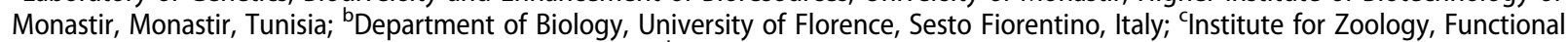 \\ Peptidomics, University of Cologne, Cologne, Germany; ${ }^{\mathrm{F}}$ Faculty of Biology, Zoology and Evolution, University of Regensburg, Regensburg, \\ Germany
}

\begin{abstract}
We investigate the influence of previously postulated biogeographic barriers in the Mediterranean Sea on the population genetic structure of a highly dispersive and continuously distributed coastal species. In particular, we examine nuclear and mitochondrial genetic variation in the marbled crab, Pachygrapsus marmoratus, across part of the African Mediterranean coast in order to assess the influence of the Siculo-Tunisian Strait on its population genetic structure. Four polymorphic microsatellite loci were genotyped for 110 individuals, collected from eight locations covering parts of the Algerian, Tunisian and Libyan coasts. In addition, mtDNA corresponding to the Cox1 gene was sequenced for 80 samples. The corresponding results show contrasting patterns of genetic differentiation. While mtDNA results revealed a homogeneous haplotype composition in our study area, microsatellite data depicted genetic differentiation among populations, but not associated with any geographic barrier. This pattern, already recorded for this species from different geographic regions, may hint at the involvement of a complex series of abiotic and biotic factors in determining genetic structure. Demographic history reconstruction, inferred from mtDNA data, supports demographic and spatial expansion for the North African metapopulation dating back to the Mid-Pleistocene and following an historical bottleneck. Comparison of these African mitochondrial sequences with new sequences from a Turkish population and previously published sequences revealed a weak but significant separation of Atlantic and Mediterranean populations across the Gibraltar Strait, which was not recorded in previous studies of this grapsid species.
\end{abstract}

ARTICLE HISTORY

Received 30 August 2015 Accepted 11 February 2016 Published online 27 May 2016

\section{RESPONSIBLE EDITOR} Gavin Gouws

\section{KEYWORDS}

Biogeographic breaks; connectivity; gene flow; genetic patchiness; larval dispersal; population genetics

\section{Introduction}

The Mediterranean Sea is characterized by a complex circulation system in which two main water bodies meet, namely the Modified Atlantic Water (MAW) and the Levantine Intermediate Water (LIW) (Astraldi et al. 1999). The hydrology is also shaped by the presence of physical barriers such as straits and channels (Béranger et al. 2004). The most important Mediterranean barriers are the Almeria-Oran Oceanographic Front, the Siculo-Tunisian Strait and the hydrographic isolation of the Aegean-lonian and Adriatic Seas (Astraldi et al. 1999; Patarnello et al. 2007). These barriers are known to restrict gene flow in some species, leading to genetic differentiation among populations (Borsa et al. 1997; Patarnello et al. 2007).
The transition zone between the Eastern and Western Mediterranean Basins constitutes one of the best documented biogeographic transitions in the Mediterranean Sea (see Arnaud-Haond et al. 2007). The Siculo-Tunisian Strait, located between Cap Bon in Tunisia and Mazara Del Vallo in Sicily (Italy), is postulated to separate these two Mediterranean basins (Quignard 1978). On both sides of this barrier, water bodies circulate with different hydrological, physical and chemical characteristics (Béranger et al. 2004). It has been documented as a geographic break, causing population genetic differentiation in several marine species (e.g. Quesada et al. 1995; Borsa et al. 1997; Bahri-Sfar et al. 2000; Nikula \& Vainola 2003; ArnaudHaond et al. 2007; Mejri et al. 2009; Zitari-Chatti et al. 2009; Kaouèche et al. 2011; Ragionieri \& Schubart

CONTACT Temim Deli temimdeli@yahoo.co.uk E Laboratory of Genetics, Biodiversity and Enhancement of Bioresources (LR11ES41), University of Monastir, Higher Institute of Biotechnology of Monastir, Av. Tahar Hadded, B.P. 74, Monastir 5000, Tunisia 
2013). Therefore, population genetic analyses across this potential barrier may contribute to the identification of the phylogeographic patterns and to depict historical events that might have shaped the genetic structure of marine species.

The African Mediterranean coast, especially the part encompassing the Tunisian and Libyan littoral, is considered as an appropriate area to study biogeographic processes because it harbours populations located west and east of the well-known biogeographic barrier of the Siculo-Tunisian Strait. Furthermore, it is hypothesized that episodes of oceanic fluctuation experienced within the central Mediterranean, specifically across the transition zone of the Siculo-Tunisian Strait, during the Pleistocene, may have affected both the genetic and demographic structure of populations for a broad variety of marine taxa (Bahri-Sfar et al. 2000; Stefanni \& Thorley 2003; Zardoya et al. 2004; Mejri et al. 2009; Zitari-Chatti et al. 2009; Kaouèche et al. 2011).

The marbled crab Pachygrapsus marmoratus (Fabricius, 1787) is one of the most widely distributed and abundant decapod crustacean species in the Mediterranean and northeastern Atlantic rocky intertidal environment, and colonizes the whole intertidal belt regardless of its width (Cannici et al. 1999). Despite its high dispersal capacity, this grapsid species represents a good model to test for population subdivision, because of its local abundance and the accumulated knowledge of its development, ecology and genetics (Cannicci et al. 1999, 2002; Cuesta \& Rodríguez 2000; Ingle \& Clark 2006; Fratini et al. 2008, 2011, 2013; Silva \& Paula 2008; Ferreira Silva et al. 2009; Silva et al. 2009a, 2009b). Factors expected to promote genetic homogeneity in this species include high fecundity (Flores \& Paula 2002), a planktonic larval period that can last more than four weeks (Cuesta \& Rodríguez 2000; Cuesta et al. 2011), and a continuous coastal distribution throughout the Mediterranean Sea, Black Sea and northeastern Atlantic coast from Brittany to Morocco, including the Canary Islands, the Azores and Madeira (Ingle 1980).

Previous studies on $P$. marmoratus revealed different patterns of mitochondrial and nuclear DNA variation and suggested relatively complex local genetic structure (Fratini et al. 2008, 2011, 2013; Silva et al. 2009b). Indeed, population genetic investigations at macroto meso-geographic scales using mtDNA failed to reveal separation among populations across known phylogeographic barriers in the Mediterranean Sea, such as the Gibraltar Strait and the Siculo-Tunisian Strait (Fratini et al. 2011). However, population genetic studies, performed on local scales and investigating polymorphism at microsatellite loci, recorded patterns of genetic differentiation among geographically close populations from the coast of Tuscany (Fratini et al. 2008, 2011) and the Tuscan archipelago (Fratini et al. 2013), with a genetic separation between the Ligurian and Tyrrhenian Seas populations. Another micro-geographic survey along the Portuguese coast, using the same nuclear markers, revealed the existence of genetic patchiness among populations of $P$. marmoratus, unrelated to any geographic gradient (Silva et al. 2009b). No genetic structure was found at a micro-geographic scale along the Tunisian coast under the likely influence of the Siculo-Tunisian Strait, but this study was based only on restricted fragment length polymorphisms (RFLPs) analyses of the mitochondrial cytochrome oxidase I (Cox1) gene (Deli et al. 2015a). The use of more variable markers, such as nuclear microsatellites, may allow for the detection of subtle population structure along the African Mediterranean coast, as these polymorphic markers provided high genetic resolution in $P$. marmoratus over small geographic scales (see Fratini et al. 2008, 2011, 2013; Silva et al. 2009b).

In light of these considerations, the main aim of the present study was to re-investigate the influence of the Siculo-Tunisian Strait on the genetic structure of populations of $P$. marmoratus along the African Mediterranean coast with molecular markers having higher resolution than those previously used by Deli et al. (2015a). For this purpose, a set of polymorphic microsatellite loci, specifically isolated and characterized for this grapsid species by Fratini et al. (2006), were genotyped in samples from eight locations covering parts of the Algerian, Tunisian and Libyan coasts.

Cox 1 sequences were also obtained for all the North African samples and for one population from southern Turkey. Furthermore, these new sequences were combined with the existing dataset by Fratini et al. (2011) (including mainly Italian, but also Atlantic populations) to investigate an overall mitochondrial geographic structure within the Mediterranean Sea and in comparison to the adjacent Atlantic Ocean. This allowed a reanalysis of possible genetic separation across the Siculo-Tunisian Strait, but also a preliminary West-East comparison with the geographic extremes, Turkey and the Canary Islands.

\section{Materials and methods}

\section{Sampling and DNA extraction}

Specimens of Pachygrapsus marmoratus were sampled during field missions from intertidal or shallow subtidal locations along the African Mediterranean coast 


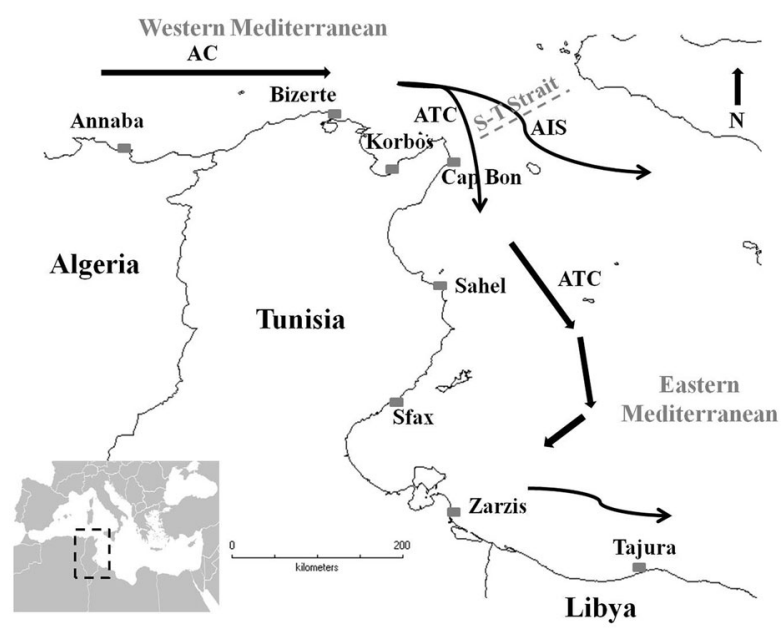

Figure 1. Sampling locations of Pachygrapsus marmoratus from the African Mediterranean coast, with sea surface currents of the studied region (according to Béranger et al. 2004). AC: Algerian Current; AIS: Atlantic Ionian Stream; ATC: Atlantic Tunisian Current.

(Figure 1). From each crab, muscle tissue was removed from a pereiopod and stored in absolute ethanol at $-30^{\circ} \mathrm{C}$ until needed. A total of 80 African crabs were used for mtDNA sequencing and 110 for microsatellite analyses (Table I). Total genomic DNA was extracted from pereiopod muscle tissue, using the Wizard $^{\circledR}$ genomic DNA purification kit (Promega).

\section{Microsatellite loci amplification and allele sizing}

A total of 110 individuals of Pachygrapsus marmoratus were screened for polymorphisms at four variable microsatellite loci (pm-101, pm-99, pm-183 and pm187), specifically isolated and described for the species (Fratini et al. 2006). DNA amplification was carried out in $10.2 \mu \mathrm{l}$ reactions with the following components: $\mathrm{ddH}_{2} \mathrm{O}$, dNTPs (0.12 mM each), PCR buffer $(1 \times), \mathrm{MgCl}_{2}(1.23 \mathrm{mM})$, forward and reverse primers (0.4 $\mu \mathrm{M}$ each), Taq polymerase (0.5 U; MBI Fermentas, St Leon-Rot, Germany) and diluted DNA. PCR thermal cycling conditions were adapted from Fratini et al. (2006), with the following profile: 35 cycles with $30 \mathrm{~s}$ for denaturation at $94^{\circ} \mathrm{C}, 45 \mathrm{~s}$ for annealing at $57-65^{\circ} \mathrm{C}$ and $180 \mathrm{~s}$ for extension at $72^{\circ} \mathrm{C}$, preceded by $5 \mathrm{~min}$ of initial denaturation at $94^{\circ} \mathrm{C}$ and followed by $30 \mathrm{~min}$ of final extension at $72^{\circ} \mathrm{C}$. For detection of polymorphisms, the forward primer for each locus was 5 -labelled, and labelled amplicons from the four loci were loaded in three different, partly multiplexed sets (pm-101 FAM + pm-99 NED; pm-183 NED; and pm-187 VIC). For each set, $1 \mu \mathrm{l}$ of each diluted PCR product was loaded with $25 \mu \mathrm{l}$ of formamide and $0.5 \mu$ l of TAMRA 500 size standard in a final volume of $26.5 \mu \mathrm{l}$ for successive dimensional analysis. Sizing was performed with reference to the internal size standard TAMRA 500 in an ABI Prism 310 Genetic Analyzer (Applied Biosystems) at the

Table I. Sampling information for the marbled crab (Pachygrapsus marmoratus), including collecting sites, countries/regions, geographic coordinates and the number of specimens examined for mtDNA and microsatellite analyses. Note: coordinates from Fratini et al. (2011) corrected.

\begin{tabular}{|c|c|c|c|c|}
\hline \multirow[b]{2}{*}{ Collection site } & \multirow[b]{2}{*}{ Country/region } & \multirow[b]{2}{*}{ Geographic coordinates } & \multicolumn{2}{|c|}{ Number of examined specimens } \\
\hline & & & mtDNA & Microsatellite loci \\
\hline \multicolumn{5}{|c|}{ Newly analysed data } \\
\hline Annaba & Algeria & $36^{\circ} 54^{\prime} \mathrm{N} 07^{\circ} 45^{\prime} \mathrm{E}$ & 10 & 10 \\
\hline Bizerte & Tunisia & $37^{\circ} 16^{\prime} \mathrm{N} 09^{\circ} 52^{\prime} \mathrm{E}$ & 8 & 20 \\
\hline Korbos & Tunisia & $36^{\circ} 49^{\prime} \mathrm{N} 10^{\circ} 34^{\prime} \mathrm{E}$ & 9 & 10 \\
\hline Cap Bon & Tunisia & $36^{\circ} 51^{\prime} \mathrm{N} 11^{\circ} 05^{\prime} \mathrm{E}$ & 12 & 20 \\
\hline Sahel & Tunisia & $36^{\circ} 10^{\prime} \mathrm{N} 10^{\circ} 49^{\prime} \mathrm{E}$ & 11 & 20 \\
\hline Sfax & Tunisia & $34^{\circ} 44^{\prime} \mathrm{N} 10^{\circ} 45^{\prime} \mathrm{E}$ & 9 & 10 \\
\hline Zarzis & Tunisia & $33^{\circ} 30^{\prime} \mathrm{N} 11^{\circ} 06^{\prime} \mathrm{E}$ & 11 & 10 \\
\hline Tajura & Libya & $32^{\circ} 52^{\prime} \mathrm{N} 13^{\circ} 20^{\prime} \mathrm{E}$ & 10 & 10 \\
\hline Beldibi & Turkey & $36^{\circ} 52^{\prime} \mathrm{N} 28^{\circ} 15^{\prime} \mathrm{E}$ & 18 & - \\
\hline \multicolumn{5}{|c|}{ Previously investigated data by Fratini et al. (2011) } \\
\hline Calafuria & Italy & $43^{\circ} 17^{\prime} \mathrm{N} 10^{\circ} 12^{\prime} \mathrm{E}$ & 15 & - \\
\hline Rocchette & Italy & $42^{\circ} 46^{\prime} \mathrm{N} 10^{\circ} 47^{\prime} \mathrm{E}$ & 14 & - \\
\hline Porto Ercole & Italy & $42^{\circ} 23^{\prime} \mathrm{N} 11^{\circ} 12^{\prime} \mathrm{E}$ & 15 & - \\
\hline Giglio Island & Italy & $42^{\circ} 21^{\prime} \mathrm{N} 10^{\circ} 55^{\prime} \mathrm{E}$ & 11 & - \\
\hline Montecristo & Italy & $42^{\circ} 20^{\prime} \mathrm{N} 10^{\circ} 19^{\prime} \mathrm{E}$ & 15 & - \\
\hline Gaeta & Italy & $41^{\circ} 11^{\prime} \mathrm{N} 13^{\circ} 35^{\prime} \mathrm{E}$ & 15 & _- \\
\hline Fusaro Lagoon & Italy & $40^{\circ} 48^{\prime} \mathrm{N} 14^{\circ} 02^{\prime} \mathrm{E}$ & 15 & - \\
\hline Crotone & Italy & $39^{\circ} 04^{\prime} \mathrm{N} 17^{\circ} 08^{\prime} \mathrm{E}$ & 16 & - \\
\hline Messina & Italy & $38^{\circ} 12^{\prime} \mathrm{N} 15^{\circ} 34^{\prime} \mathrm{E}$ & 16 & - \\
\hline St Florent & Corsica & $42^{\circ} 41^{\prime} \mathrm{N} 09^{\circ} 16^{\prime} \mathrm{E}$ & 15 & - \\
\hline Tarragona & Spain & $41^{\circ} 07^{\prime} \mathrm{N} 01^{\circ} 16^{\prime} \mathrm{E}$ & 20 & - \\
\hline Valencia & Spain & $39^{\circ} 26^{\prime} \mathrm{N} 00^{\circ} 19^{\prime} \mathrm{W}$ & 20 & - \\
\hline Cala Iris & Morocco & $35^{\circ} 09^{\prime} \mathrm{N} 04^{\circ} 21^{\prime} \mathrm{W}$ & 15 & - \\
\hline Sesimbra & Portugal & $38^{\circ} 24^{\prime} \mathrm{N} 09^{\circ} 04^{\prime} \mathrm{W}$ & 18 & - \\
\hline Matorral & Fuerteventura & $28^{\circ} 02^{\prime} \mathrm{N} 14^{\circ} 19^{\prime} \mathrm{W}$ & 18 & _- \\
\hline
\end{tabular}


University of Regensburg, using GENOTYPER 3.5 and GENESCAN 3.5 (Applied Biosystems).

\section{Mitochondrial DNA amplification and sequencing}

The mitochondrial cytochrome oxidase subunit I (Cox 1 ) gene, consisting of approximately 1500 basepairs (bp), was amplified using the primers $\mathrm{COL} 6 \mathrm{a}$ and $\mathrm{COH} 16$, specifically designed for brachyuran crab species (see Schubart 2009). The PCR reaction mix contained: $\mathrm{ddH}_{2} \mathrm{O}$, dNTPs (0.12 mM each), PCR buffer ( $\left.1 \times\right), \mathrm{MgCl}_{2}$ $(4 \mathrm{mM})$, both primers $(0.24 \mu \mathrm{M}$ each), Taq polymerase (0.5 U; MBI Fermentas), and diluted genomic DNA, adding up to a final master mix volume of $25 \mu$ l. PCR amplifications were carried out with an initial denaturation phase of $4 \mathrm{~min}$ at $94^{\circ} \mathrm{C}$, followed by 40 cycles, each composed of $45 \mathrm{~s}$ of denaturation at $95^{\circ} \mathrm{C}, 60 \mathrm{~s}$ of annealing at $52^{\circ} \mathrm{C}$ and $90 \mathrm{~s}$ of extension at $72^{\circ} \mathrm{C}$. These cycles were followed by $8 \mathrm{~min}$ of final extension at $72^{\circ} \mathrm{C}$. PCR products were loaded on $1.5 \%$ agarose gel with GelRed staining and visualized under UV light. Only strong products were outsourced for sequencing with primer COL6a to LGC Genomics (Berlin). The sequences obtained were visually corrected with Chromas Lite 2.1.1 (Technelysium Pty Ltd 2012), aligned with BIOEDIT (Hall 1999) and trimmed to a $739 \mathrm{bp}$ fragment for subsequent analyses.

\section{Statistical analysis of microsatellite data}

Nuclear microsatellite loci were investigated in North African populations of Pachygrapsus marmoratus from the Algerian, Tunisian and Libyan coasts. Deviations from Hardy-Weinberg equilibrium (HWE) in the marbled crab populations were tested using the Markov chain method with 5000 iterations as implemented in GENEPOP 4.2 (Raymond \& Rousset 1995). Genetic variability (Ar: allelic richness, Ho: observed heterozygosity and He: expected heterozygosity) at the typed microsatellite loci, as well as Weir \& Cockerham's (1984) estimation of $F_{\mathrm{IT}}, F_{\mathrm{ST}}$ and $F_{\mathrm{IS}}$, were calculated using FSTAT 9.2.3.2 (Goudet 1995). Genetic diversity measures in each population (Ho: observed heterozygosity, He: expected heterozygosity and $F_{\mathrm{IS}}$ : inbreeding coefficient) were estimated with GENEPOP using the Markov chain parameter with 10,000 dememorizations, 20 batches and 5000 iterations per batch. Since all populations showed highly significant heterozygote deficiencies, the dataset was checked for genotyping errors (i.e. null alleles) by means of Equation 2 from Brookfield (1996), as implemented in MICROCHECKER 2.2.3 (van Oosterhout et al. 2004). We then used the software FREENA to compute a genotype dataset corrected for null alleles, following the INA method described in Chapuis \& Estoup (2007).

Genetic differentiation was estimated by means of the exact test of population differentiation (Raymond \& Rousset 1995), as implemented in GENEPOP. This test verifies the existence of differences in allele frequencies at each locus and for each population. Single locus $P$ values were calculated using a Markov chain with 10,000 dememorizations, 100 batches and 5000 iterations per batch, combined over loci, using the Fisher exact test (Fisher 1935). The existence of genetic differentiation was also assessed by one-level AMOVA (Excoffier et al. 1992), using ARLEQUIN 3.1. Correlations between genetic ( $F_{\mathrm{ST}}$ values) and geographic distances were assessed by the Mantel Test (Mantel 1967), as implemented in ARLEQUIN, with 10,000 random permutations.

An additional two-level AMOVA was performed, grouping populations according to a specific biogeographic hypothesis: African western Mediterranean versus African eastern Mediterranean. The exact test $(G)$ of genetic differentiation, implemented in GENEPOP, was applied to the two groups of populations already tested by the structured AMOVA in order to assess both genic and genotypic differentiation.

The Bayesian approaches implemented in the two software packages, STRUCTURE 2.3.4 (Pritchard et al. 2000) and BAPS 3.2 (Corander et al. 2003), were also used to identify clusters of genetically similar populations based on the nuclear microsatellite data. BAPS generally tends to recover more clusters than STRUCTURE, and it has been suggested that both approaches should be used, particularly where levels of differentiation between populations may be low (Latch et al. 2006). For STRUCTURE analysis, the admixture model was processed using correlated allele frequencies. The probability of the number of populations $(K)$ for the pooled data was estimated by fixing prior values of $K$ ( $K$ was set from one to eight in our study) and comparing the $\operatorname{Ln} P(D)$ (the log-probability of the data) and the loglikelihood of the data. Three replicates for each $K$ were independently performed, giving reproducible results. The analysis was run for 500,000 generations with a burn-in length of 20,000 iterations. For the BAPS analysis, the number of genetically diverged groups $(K)$ varied from $K=1$ to $K=8$ in both clustering of individuals and clustering of groups of individuals. In the admixture analysis based on mixture clustering, 200 iterations were used for the number of times that individuals in the data were analysed using different simulated allele frequencies for the estimation of reference individuals, as suggested by Corander et al. (2005). 
Genotypic structure analysis was also assessed by ordinating genotypes in multidimensional space by principal component analysis (PCA) of gene frequency data, using the program PCA-GEN 1.2.1 (Goudet 1999). Individuals were plotted by scores along the two principal axes (PC-I and PC-II), explaining the cumulative percentage of the total genetic diversity, testing for the existence of population groupings. Genotypic assignment was also assessed by GENECLASS 2.0 (Piry et al. 2004). The most probable origin of each individual was calculated by comparing the likelihood of the multi-locus genotype of a given individual in a set of pre-determined populations. The Bayesian method, proposed by Rannala \& Mountain (1997), was chosen, together with a threshold of 0.05. GENECLASS also allowed for the detection of the number of migrants. The frequency-based method, described by Paetkau et al. (1995), was used and a threshold of 0.01 was set. For both tests, the rejection probability was obtained by simulating 10,000 individuals from allelic frequencies based on the simulation algorithm of Paetkau et al. (2004).

In order to test for evidence of a recent population bottleneck in African Mediterranean populations of P. marmoratus, we applied the BOTTLENECK test (Cornuet \& Luikart 1996), using the heterozygosity excess method of Luikart et al. (1998), as implemented in BOTTLENECK 1.2.02 (Piry et al. 1999). This program generates the heterozygosity of each locus expected under mutation-drift equilibrium, given the observed number of alleles (Heq) under the three mutation models: the infinite allele model (IAM), the two phase mutation model (TPM) and the stepwise mutation model (SMM), using 10,000 simulations. The obtained Heq values are then averaged across loci and compared with the observed level of heterozygosity $(\mathrm{Ho})$. The SMM and TPM are most appropriate for microsatellite data (Luikart \& Cornuet 1998), with the TPM providing a more realistic picture of mutational events in microsatellite loci (Di Rienzo et al. 1994; Piry et al. 1999). For the TPM, 70 multi-step mutations were set, with a variance among multi-steps of $12 \%$, as recommended for microsatellites (Piry et al. 1999), and statistical significance based on 1000 replications was obtained. In a population at mutation-drift equilibrium (i.e. the effective size of which has remained constant in the past), there is approximately an equal probability that a locus shows a heterozygosity excess or a heterozygosity deficit. We then recorded the number of loci for which Ho was greater than Heq and determined whether the overall set of deviations was statistically significant using the sign rank and Wilcoxon tests (Luikart et al. 1998).

\section{Statistical analysis of mtDNA data}

\section{Data analysis procedure}

Genetic analyses were carried out using two alignments: (1) a long alignment of 739 base pairs (bp), with sequences from North African populations, and (2) a shorter alignment of $596 \mathrm{bp}$ for comparison and population genetic investigation of Pachygrapsus marmoratus across a wider geographic scale. The latter included the European Atlantic and western Mediterranean dataset previously investigated by Fratini et al. (2011) and the newly examined North African and Turkish sequences (Table I).

\section{Genetic diversity and population structure}

The nucleotide composition was assessed using MEGA 5.2 (Tamura et al. 2011). Measurements of DNA polymorphism, including the number of haplotypes, haplotype diversity $(h ;$ Nei 1987$)$ and nucleotide diversity $(\pi ;$ Tajima 1983; Nei 1987), were calculated for each population using DNASP 5.10 (Librado \& Rozas 2009). Intraspecific evolutionary relationships among the Cox 1 haplotypes of Pachygrapsus marmoratus, for both alignment datasets, were estimated using the software TCS 1.21 (Clement et al. 2000).

We measured levels of population subdivision using both unordered $\left(G_{S T}\right)$ and ordered alleles $\left(N_{S T}\right)$ in order to assess the relationship between phylogeny and the geographic distribution of haplotypes. These analyses were carried out using a distance matrix (number of polymorphic sites that differed between haplotypes) that was based on the larger Cox1 data for Pachygrapsus marmoratus. Both population differentiation parameters $\left(G_{S T}\right.$ and $\left.N_{S T}\right)$ were estimated following the methods described by Pons \& Petit (1995, 1996), using the program PERMUT \& CPSRR 2.0 (Pons \& Petit 1996). $G_{S T}$ is based solely on haplotype frequencies, whereas $N_{\text {ST }}$ also takes into account the genetic relationship among haplotypes. An $N_{S T}$ higher than the $G_{S T}$ usually indicates that closely related haplotypes are more often found in the same area than less closely related haplotypes (Pons \& Petit 1996; Petit et al. 2005). These two parameters were compared statistically using the U-test (Pons \& Petit 1996).

Evidence of population genetic differentiation within each data alignment was assessed by onelevel AMOVAs (Excoffier et al. 1992), as implemented in ARLEQUIN 3.1 (Excoffier et al. 2005), based on nucleotide diversity and haplotype frequency. The extent of genetic differentiation between populations was estimated using the fixation indices: $\Phi_{\mathrm{ST}}$ (based on a Tajima-Nei model, suggested for unequal 
nucleotide frequencies, as observed in our dataset; Tajima \& Nei 1984) and $F_{\text {ST }}$ (computed using haplotypic frequencies). Significance levels of pairwise genetic distances, estimated among populations, were assessed by a randomization procedure with 10,000 permutations. Analyses of molecular variance (two-level AMOVA) were also used to examine population genetic structure of $P$. marmoratus along the WestEast geographic gradient, testing for the separation across (1) the Gibraltar Strait (Atlantic vs. Mediterranean) and (2) across both the Gibraltar and Siculo-Tunisian Straits (Atlantic vs. Western Mediterranean vs. Eastern Mediterranean). A test of isolation by distance, for the whole dataset, was assessed by the Mantel test (Mantel 1967), as implemented in the program AIS 1.0 (Alleles in Space; Miller 2005). The statistical significance of the test was assessed assuming 10,000 random permutations.

\section{Demographic history}

Signatures of population demographic changes were investigated in African Mediterranean Pachygrapsus marmoratus using three neutrality tests: Tajima's $D$ (Tajima 1989), Fu's Fs (Fu, 1997), and Ramos-Onsins \& Rozas's $R_{2}$ (Ramos-Onsins \& Rozas 2002). Tajima's $D$ and Fu's Fs statistics were used to determine whether data departed from neutrality due to factors such as a population bottleneck or sudden expansion. The examination of deviation from neutrality by both $D$ and Fs indices was based on 1000 coalescent simulations, as implemented in ARLEQUIN. Significant negative $D$ and Fs values can be interpreted as signatures of population expansion. The $R_{2}$ statistic of Ramos-Onsins \& Rozas (2002), which has more statistical power when population sizes are small, was calculated using a coalescent simulation algorithm implemented in DNASP, with 1000 simulations. Demographic changes in $P$. marmoratus were also examined by calculating the Harpending's raggedness index rg (Harpending 1994) of the observed mismatch distribution for each of the populations, according to the population expansion model implemented in ARLEQUIN. The significance of this measure, which quantifies the smoothness of the observed mismatch distribution, was tested using parametric bootstrapping (10,000 replicates). Tajima's $D$, Fu's Fs, Ramos-Onsins \& Rozas's $R_{2}$ and Harpending's raggedness index $r g$ were calculated for each population and the whole dataset.

To provide other estimates of population size changes, we also examined site mismatch distributions for the whole dataset. Contrasting plots of observed and theoretical distributions of site differences yield insight into past population demographics. The expected mismatch distributions under a sudden expansion model were computed in ARLEQUIN. The sum of squared deviations (SSD) between observed and expected distributions was used as a measure of fit, and the probability of obtaining a simulated SSD greater than or equal to the expected was computed by randomization. If this probability was $>0.05$, the expansion model was accepted. Graphical representation was made by means of the growth-decline model implemented in DNASP. It was investigated whether $P$. marmoratus underwent a range expansion by the spatial expansion model (Excoffier 2004) in ARLEQUIN. The mismatch distribution analysis also provides an estimation for the expansion parameters Tau $(\tau)$, Theta $0\left(\theta_{0}\right)$ and Theta $1\left(\theta_{1}\right)$, under a demographic or spatial expansion hypothesis. The value of $\tau$ can be used to calculate the time $(t)$ at which the demographic or spatial expansion began, using the formula $t=\tau / 2 u$ (Rogers \& Harpending 1992), with $u$ defined as the mutation rate per site per year (Li 1977). A conventional mutation rate for the Cox 1 gene in brachyuran Crustacea (1.66\% per million years; Schubart et al. 1998) was used in our analysis.

The magnitude of historical demographic events for the African Mediterranean population of $P$. marmoratus was investigated using Bayesian Skyline Plots (BSP; Drummond et al. 2005). In comparison with simple parametric and older coalescent demographic methods, the smoother estimates and sensitivity of this method, together with a credibility interval, provide a realistic population size function and enable retrieval of more details than just summary statistics. Analyses were run in BEAST 1.7.5 (Drummond et al. 2012) using a GTR model and a strict molecular clock. The Markov chain Monte Carlo simulations were run with $30,000,000$ iterations, while genealogies and model parameters were sampled every 1000 iterations. The first 3,000,000 iterations were discarded as burn-in, whereas the remaining results were combined in LogCombiner (Drummond et al. 2012) and summarized as BSPs after analysing their convergence in TRACER 1.5 (Rambaut \& Drummond 2007).

\section{Results}

\section{Micro-geographic scale}

\section{Microsatellites}

Overall, a total of 85 alleles were detected at the four genotyped microsatellite loci. All loci were polymorphic, with the number of alleles per locus ranging from 17 (locus pm-183) to 25 (locus pm-101). The mean 
Table II. The exact test for Hardy-Weinberg equilibrium in the marbled crab (Pachygrapsus marmoratus) and genetic diversity measures in each population, based on the analysis of microsatellite loci.

\begin{tabular}{llcccr}
\hline Population & Size & $P$ & $H o$ & $H e$ & \multicolumn{1}{c}{$F_{\text {IS }}$} \\
\hline Annaba & 10 & $0.269 \mathrm{~ns}$ & 0.800 & 0.818 & 0.022 \\
Bizerte & 20 & $0.056 \mathrm{~ns}$ & 0.750 & 0.811 & 0.075 \\
Korbos & 10 & $0.567 \mathrm{~ns}$ & 0.775 & 0.748 & -0.035 \\
Cap Bon & 20 & $0.168 \mathrm{~ns}$ & 0.700 & 0.712 & 0.017 \\
Sahel & 20 & $0.438 \mathrm{~ns}$ & 0.775 & 0.794 & 0.024 \\
Sfax & 10 & $0.593 \mathrm{~ns}$ & 0.825 & 0.798 & -0.033 \\
Zarzis & 10 & $0.467 \mathrm{~ns}$ & 0.800 & 0.781 & -0.023 \\
Tajura & 10 & $0.081 \mathrm{~ns}$ & 0.800 & 0.841 & 0.049
\end{tabular}

$P$ : the $P$-value of departure from the Hardy-Weinberg equilibrium for each population; ns: no significant departure from Hardy-Weinberg equilibrium; Ho: observed heterozygosity; He: expected heterozygosity; $F_{15}$ : inbreeding coefficient; Corrected genotype dataset for null alleles was computed following the INA method (Chapuis \& Estoup 2007).

number of alleles per locus was 21. Based on the original dataset, all populations strongly deviated from HardyWeinberg equilibrium (HWE), with an excess of homozygotes, at all examined loci. The software MICROCHECKER suggested the presence of null alleles for these loci. Therefore, we corrected the original matrix for null alleles. Re-analysis of the revised dataset revealed no significant departure from HWE for each population (Table II), as well as for the whole sample $(P=0.089)$. The mean observed and expected heterozygosities across loci were $0.778 \pm 0.128$ and $0.788 \pm 0.123$, respectively. The mean allelic richness across loci was $9.170 \pm$ 1.969. Weir \& Cockerham's (1984) estimation of F-statistics showed that the highest values of $F_{\mathrm{IT}}(0.084 \pm$ $0.048)$ and $F_{\mathrm{ST}}(0.040 \pm 0.016)$ corresponded to locus pm-183, whereas pm-101 exhibits the highest value of $F_{\text {IS }}(0.067 \pm 0.024)$. Overall, $F_{\mathrm{IT}}$ values were higher than those recorded for $F_{\mathrm{IS}}$ within the examined loci. The observed and expected heterozygosities and the $F_{\text {IS }}$ estimates within the eight studied populations are shown in Table II. The mean observed and expected heterozygosities across populations were $0.778 \pm 0.028$ and $0.787 \pm$ 0.030 , respectively. Heterozygosity deficit, as measured by Wright's $F_{\text {IS }}$ (Table II), showed low levels in most populations when averaged across loci, ranging from -0.035 (population at Korbos) to 0.075 (population at Bizerte). The average value of $F_{\mathrm{IS}}$ across populations was 0.012 \pm 0.031 , indicating a low heterozygote deficiency.

Overall, our results showed highly significant genetic differentiation among populations. Based on the outcome of the Fisher exact test, we rejected the hypothesis of genetic homogeneity in the distribution of allele frequencies for the entire microsatellite dataset $\left(x^{2}=\infty, \quad d f=8, \quad P<0.001\right)$. The one-level AMOVA also confirmed the hypothesis of a partitioning of genetic variation among populations $\left(F_{\mathrm{ST}}=0.014\right.$, $\mathrm{df}=219, \quad P<0.001)$. No relationship was found between genetic and geographic distances $(r=$
$-0.095, P=0.704)$ by means of the Mantel test, excluding the hypothesis of isolation by distance to explain population separation. Population genetic structure was examined by means of the two-level AMOVA, grouping populations according to their geographic origin: African western Mediterranean (Annaba, Bizerte, Korbos and Cap Bon) versus African eastern Mediterranean (Sahel, Sfax, Zarzis and Tajura). Our results showed a lack of genetic subdivision across the Siculo-Tunisian Strait $\left(F_{\mathrm{CT}}=-0.001, \mathrm{df}=219, P=\right.$ 0.659). Conversely, the exact test of genetic differentiation $(\mathrm{G})$ showed weak but significant genic differentiation $\left(X^{2}=16.973, \mathrm{df}=8, P=0.030\right)$ between these two groups of populations. Nevertheless, comparison at the genotypic level did not lead to the same result $\left(X^{2}=15.084, \mathrm{df}=8, P=0.057\right)$.

A lack of population genetic structure was revealed based on genotypic assignment. The Bayesian clustering program STRUCTURE recorded a consistent decrease in the $\operatorname{LnP}(\mathrm{D})$ (the log-probability of data) from $\mathrm{K}=1$ $(\operatorname{LnP}(D)=-2057.1)$ to $\mathrm{K}=8(\operatorname{LnP}(\mathrm{D})=-2158.2)$, supporting a single population. Although BAPS analysis yielded three clusters, specimens of the examined populations were shown to mix and it was not possible to achieve a strong clustering pattern. However, cluster 3 seemed to differentiate the two populations of Korbos and Tajura, based on the average admixture coefficients for the specimens according to their clusters (Figure 2). This result was consistent with that given by the statistical approach of PCA-GEN software. The result of the PCA on the genotypes, ordered in the space defined by the two main axes (PC-I and PC-II, explaining 51.04\% of the total genetic diversity), did not show significant groupings, even though populations like Bizerte and Tajura were shown to be separated from the others by means of axis I and II, respectively (Figure 3). Furthermore, only $16.4 \%$ of individuals were assigned by GENECLASS (with a quality index of $17.21 \%$ ) to the populations from which they were sampled. GENECLASS also

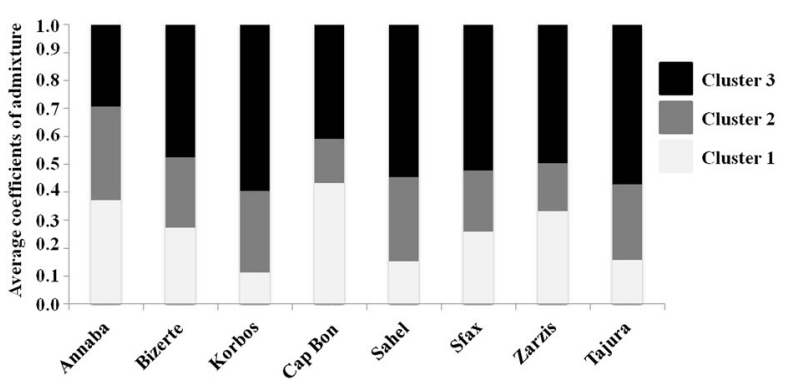

Figure 2. BAPS analysis depicting average coefficients of admixture for Pachygrapsus marmoratus specimens belonging to eight populations according to their clusters. 


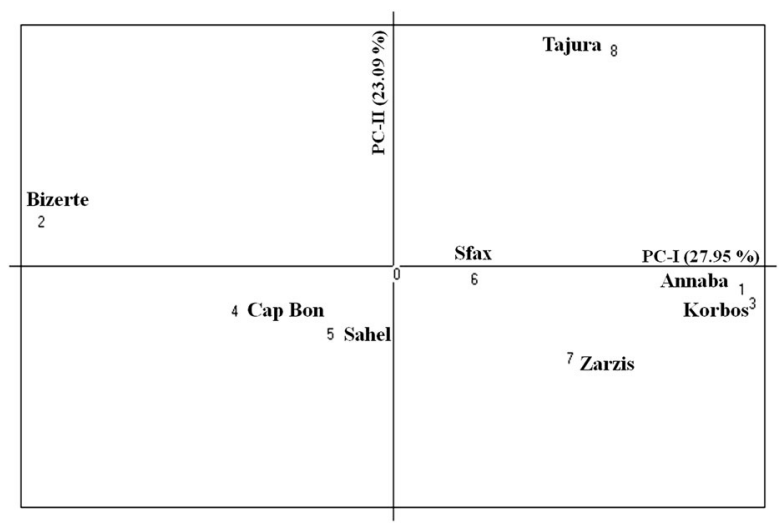

Figure 3. Scores of microsatellite genotypes of Pachygrapsus marmoratus populations, plotted on the first two axes (PC-I vs. PC-II) of a principal component analysis (PCA) performed using PCA-GEN version 1.2.1.

revealed that eight individuals $(P<0.01)$ were potential first generation migrants.

The hypothesis of a possible bottleneck in the North African metapopulation of Pachygrapsus marmoratus was tested. The results of bottleneck analysis using the sign rank test and Wilcoxon test for each of three mutation models are depicted in Table III. The probability values from the Wilcoxon test for the IAM, TPM and SMM models indicated the acceptance of mutation-drift equilibrium under all the models. Indeed, the Wilcoxon test revealed no significant patterns of heterozygosity excess $(P=0.968)$. Accordingly, these results excluded the hypothesis of a recent genetic bottleneck.

\section{Mitochondrial DNA}

Genetic analyses of the African Mediterranean populations of Pachygrapsus marmoratus were carried out using the longer alignment of $739 \mathrm{bp}$, generated for the mtDNA cytochrome oxidase I (Cox1) gene from
80 individuals. In all, 31 nucleotide sites were variable, of which 13 were parsimony-informative and 18 were autapomorphic (singletons). Among these sequences, 32 haplotypes were identified (Figure 4a). The nucleotide composition of the analysed fragment showed an $A-T$ bias $(C=20.29 \% ; \quad T=36.80 \% ; \quad A=25.37 \% ; \quad G=$ $17.54 \%)$, as previously mentioned for invertebrate mitochondrial DNA (Simon et al. 1994). Overall, genetic diversity analysis of the mitochondrial dataset showed high haplotypic diversity $(h=0.812$ $\pm 0.044)$ and low nucleotide diversity $(\pi=0.0029 \pm$ 0.000 ) (Table IV). The statistical parsimony procedure yielded one network with several connections (Figure 4a). The network had a star-like shape in which the proposed ancestral haplotype (haplotype 19 , found in the population of Korbos) occupied a central position (Figure 4a). Most of the haplotypes differed by few mutations. The most common haplotype (haplotype 1), found in 34 specimens from all populations, was separated from the ancestral haplotype by one mutational step. The two most divergent haplotypes (28 and 29) were from the population of Tajura, being separated from the ancestral haplotype by at least five mutational steps. The population of Korbos was characterized by the highest genetic variability with the existence of nine haplotypes, of which seven were site-specific.

The one-level AMOVA showed a lack of population genetic structure among African Mediterranean populations of $P$. marmoratus $\left(\Phi_{\mathrm{ST}}=0.014, \mathrm{df}=79, P=\right.$ 0.215 , based on Tajima-Nei distances; $F_{\mathrm{ST}}=-0.006$, $\mathrm{df}=79, P=0.593$, based on haplotype frequency). All pairwise comparisons, estimated from both genetic divergence and haplotype frequencies, were not significant (data not shown), except the one between the population of Korbos and the population of Sahel $\left(\Phi_{\mathrm{ST}}=0.149, P<0.05\right)$.

Table III. Genetic bottleneck analysis within the North African metapopulation of Pachygrapsus marmoratus based on three microsatellite evolutionary models.

\begin{tabular}{|c|c|c|c|c|c|c|c|c|c|c|c|c|}
\hline \multirow[b]{2}{*}{ Locus } & \multicolumn{4}{|c|}{ Under the IAM (Infinite allele model) } & \multicolumn{4}{|c|}{ Under the TPM (Two phase model) } & \multicolumn{4}{|c|}{ Under the SMM (Stepwise mutation model) } \\
\hline & Heq & S.D. & $\mathrm{DH} / \mathrm{sd}$ & Prob & Heq & S.D. & $\mathrm{DH} / \mathrm{sd}$ & Prob & Heq & S.D. & $\mathrm{DH} / \mathrm{sd}$ & Prob \\
\hline pm101 & 0.916 & 0.024 & -2.736 & 0.016 & 0.941 & 0.012 & -7.496 & 0.001 & 0.948 & 0.012 & -8.138 & 0.003 \\
\hline pm99 & 0.904 & 0.029 & 2.014 & 0.000 & 0.935 & 0.013 & 2.172 & 0.000 & 0.943 & 0.012 & 1.619 & 0.000 \\
\hline pm183 & 0.860 & 0.046 & -2.787 & 0.019 & 0.903 & 0.022 & -7.803 & 0.000 & 0.919 & 0.014 & -13.28 & 0.000 \\
\hline pm187 & 0.885 & 0.039 & -8.177 & 0.000 & 0.922 & 0.015 & -23.596 & 0.000 & 0.933 & 0.015 & -23.55 & 0.000 \\
\hline \multirow{2}{*}{\multicolumn{3}{|c|}{$\begin{array}{l}\text { Sign rank test (number of loci } \\
\text { with heterozygosity excess) }\end{array}$}} & Expected & 2.42 & & & Expected & 2.33 & & & Expected & 2.37 \\
\hline & & & Observed & 1 & & & Observed & 1 & & & Observed & 1 \\
\hline & & & Probability & 0.172 & & & Probability & 0.199 & & & Probability & 0.189 \\
\hline \multicolumn{3}{|c|}{ Wilcoxon test (probability) } & & 0.968 & & & & 0.968 & & & & 0.968 \\
\hline
\end{tabular}

Heq: expected heterozygosity at the mutation-drift equilibrium, generated from the number of alleles at a locus and the sample size; S.D.: the standard deviation (SD) of the mutation-drift equilibrium distribution of the heterozygosity; DH/sd: the standardized differences for each locus ((Ho-He)/SD); Prob: the distribution obtained through simulation enables also the computation of a $P$-value for the observed heterozygosity. Test of whether observed heterozygosity deviates from that expected under mutation-drift equilibrium, using the three mutation models, was assessed by the probability of Heterozygosity excess $(P)$ yielded by the Wilcoxon test. 
(a)
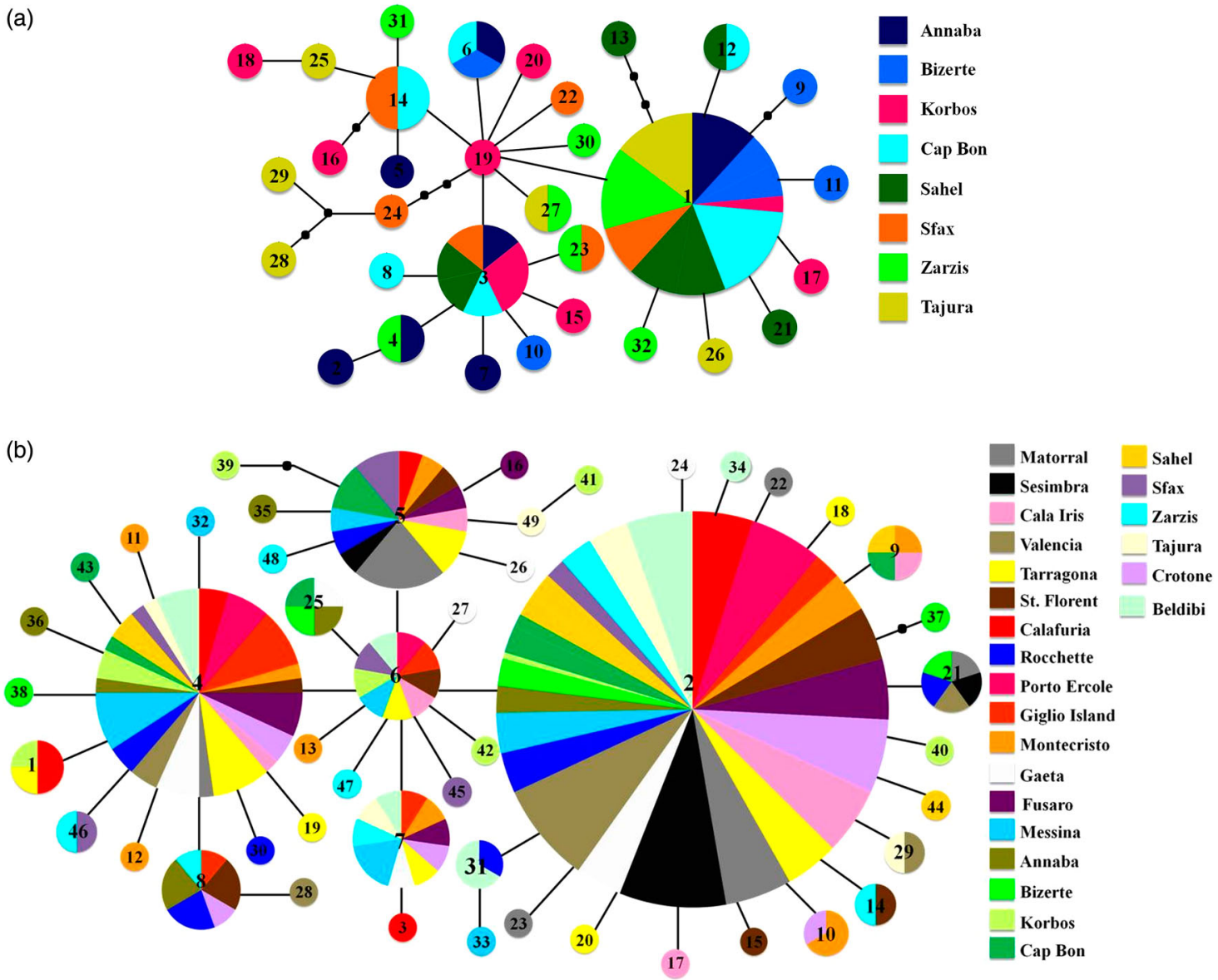

Figure 4. TCS haplotype network of Pachygrapsus marmoratus, based on the alignment of $739 \mathrm{bp}$ (a) and 596 bp (b) of the mitochondrial gene Cox1, showing the relationships among the recorded haplotypes across different investigated regions. Haplotypes 19 (a) and 6 (b) correspond to the ancestral haplotype. Each line between two points represents one mutational step. Circle sizes depict proportions of haplotypes; the smallest corresponds to 1 and the largest to 34 (a) and 182 (b) individuals. Notation: Each network includes its own haplotype organization driven from the corresponding alignment.

Population demographic history was reconstructed using three neutrality tests, mismatch distribution analysis and BSP analysis. The applied neutrality tests revealed significant deviations from mutation-drift equilibrium for the populations of Annaba, Bizerte, Korbos, Cap Bon, Zarzis and Tajura, showing mainly significant results for $F_{S}$ and $R_{2}$ tests (Table IV) and suggesting recent population expansion events. Moreover, the negative and significant values of Tajima's $D$ and Fu's $F_{S}$ tests, as well as the significant value of Ramos-Onsins \& Rozas $R 2$, together with the small and non-significant value of Harpending's raggedness index $r g$, revealed significant deviations from neutrality for the whole

Table IV. Genetic diversity and historical demographic results for Pachygrapsus marmoratus populations from the African Mediterranean coast, based on the analysis of the mtDNA Cox1 gene.

\begin{tabular}{|c|c|c|c|c|c|c|c|c|}
\hline Population & $N$ & $\mathrm{Na}$ & $h$ & $\pi(\%)$ & $D$ & $F_{S}$ & $R_{2}$ & rg \\
\hline Annaba & 10 & 7 & $0.86 \pm 0.10$ & $0.32 \pm 0.03$ & -0.61 & -2.67 & 0.12 & 0.12 \\
\hline Bizerte & 8 & 5 & $0.78 \pm 0.15$ & $0.26 \pm 0.02$ & -1.35 & -1.23 & 0.12 & 0.06 \\
\hline Korbos & 9 & 8 & $0.97 \pm 0.06$ & $0.37 \pm 0.03$ & -0.74 & -4.62 & 0.11 & 0.06 \\
\hline Cap Bon & 12 & 6 & $0.75 \pm 0.12$ & $0.22 \pm 0.02$ & -0.67 & -1.87 & 0.11 & 0.22 \\
\hline Sahel & 11 & 5 & $0.70 \pm 0.13$ & $0.21 \pm 0.02$ & -1.40 & -0.97 & 0.13 & 0.03 \\
\hline Sfax & 9 & 6 & $0.88 \pm 0.09$ & $0.32 \pm 0.03$ & -0.85 & -1.71 & 0.14 & 0.32 \\
\hline Zarzis & 11 & 7 & $0.81 \pm 0.11$ & $0.29 \pm 0.02$ & -1.26 & -2.65 & 0.08 & 0.17 \\
\hline Total & 80 & 32 & $0.81 \pm 0.04$ & $0.29 \pm 0.00$ & -2.03 & -27.12 & 0.03 & 0.05 \\
\hline
\end{tabular}

Values reported for each population and for the total dataset are: sample size $(N)$, number of haplotypes $(\mathrm{Na})$, haplotype $(h)$ and nucleotide $(\pi)$ diversity Tajima's $D$ test $(D)$, Fu's $F_{S}$ test $\left(F_{S}\right)$, Ramos-Onsins and Rozas's $R_{2}$ test $\left(R_{2}\right)$, and mismatch distribution raggedness index $(r g)$. Nucleotide diversity $(\pi)$ was calculated in per cent. Significant values are in bold. 
(a)

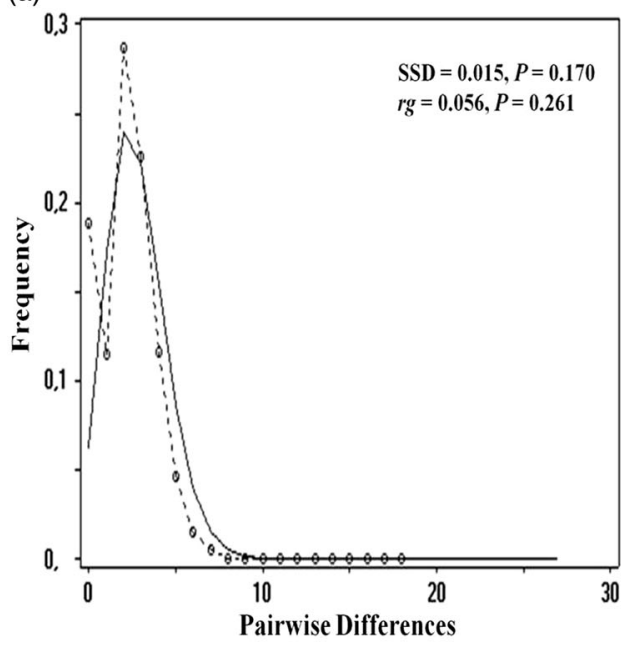

(b)

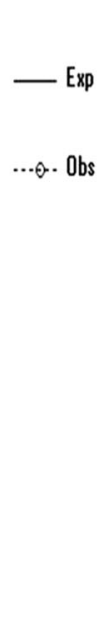

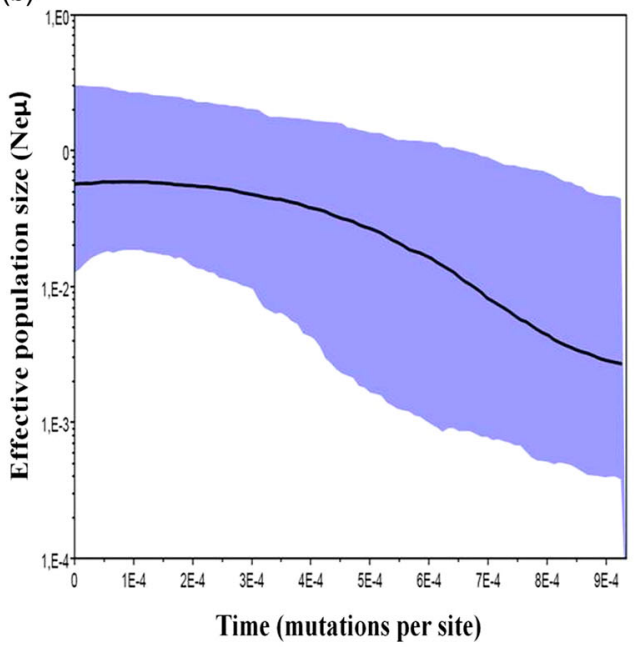

Figure 5. Mismatch distribution (a) and Bayesian skyline plot (BSP, implemented in BEAST) (b) for the North African populations of Pachygrapsus marmoratus. (a) Observed frequencies (dotted line) were compared with the expected frequencies (continuous line), estimated by the growth-decline model implemented in DNASP. The demographic expansion parameters used, $\tau$ and $\theta_{\text {initial, }}$ were calculated in ARLEQUIN $\left(\tau=2.781\right.$ and $\left.\theta_{\text {initial }}=0.000\right) ; \theta_{\text {final }}$ value was fixed at 1000 to simulate the infinite. The two demographic indices SSD and $r g$, provided for the observed mismatch distributions, were calculated under the assumption of a demographic expansion model, implemented in ARLEQUIN. (b) BSP showing changes in effective population size (expressed as effective population size $[\mathrm{Ne}]$ multiplied per generation time $[\mu]$ ) over time (measured in mutations per site). The thick solid line depicts the median estimate, and the margins of the surrounding area represent the highest $95 \%$ posterior density intervals.

dataset (Table IV and Figure 5a), consistent with a scenario of a sudden demographic expansion. The unimodal mismatch distribution obtained for the North African metapopulation of $P$. marmoratus (Figure 5a) also suggested a recent demographic expansion. Statistical analysis of the mismatch distribution supported both models of demographic (SSD $=0.015 ; P=0.170)$ and spatial expansion (SSD $=0.009 ; P=0.545$, associated with a strictly positive migration rate: $M=7.810$ [2.575-99999, for a $95 \%$ confidence interval]). Under the assumption of a sudden demographic expansion, the value of $\tau$ for the whole sample was 2.781 (95\% confidence interval: 1.111-4.494). Thus, assuming a Cox 1 mutation rate of $1.66 \%$ per million years (Schubart et al. 1998), the most recent population expansion began at around 0.837 million years ago. Under the spatial expansion hypothesis, the value of $\tau$ decreased to 2.619 (95\% confidence interval: 0.850-4.097), corresponding to an expansion time of 0.788 million years ago.

Historical demography of the North African population of $P$. marmoratus was also inferred from the coalescent approach in the BSP analysis. The pattern of effective population size change over time was shown to be a remarkably progressive increase (Figure 5b) and invoked the possible scenario of population demographic recovery following an historical bottleneck (Hoffman et al. 2011).

\section{Macro-geographic scale}

The inclusion of previously published data allowed for the analysis of 336 Cox 1 sequences (Table I) with an alignment length of $596 \mathrm{bp}$. A total of 41 variable sites (17 informative) defined 49 haplotypes. Among these, 16 haplotypes were newly detected in this study. Nucleotide composition of the analysed fragment was found to be unbalanced $(C=20.97 \%$; $T=$ $35.91 \% ; A=25.08 \% ; G=18.04 \%)$. Overall haplotype diversity $(h)$ and nucleotide diversity $(\pi)$, calculated for the investigated geographic range, were $0.684 \pm 0.020$ and $0.0024 \pm 0.000$, respectively. The haplotype network had a star-like shape, centred on two main haplotypes (2 and 4; Figure 4b). Haplotype 6, found at the junction of the branches connecting the main haplotypes, occupied a central position and was therefore proposed to be the ancestral haplotype (Figure 4b). Haplotype 2, found in 182 individuals, was present in all populations. In contrast, haplotype 4, found in 44 specimens, was not recorded from the Portuguese location of Sesimbra or the Tunisian populations of Bizerte and Zarzis. Calculations of $N_{S T}(0.015)$ and $G_{S T}$ (0.012) revealed that the $N_{S T}$ value was not significantly higher than the $G_{\mathrm{ST}}$ value ( $U$-test $\left.=0.70, P=0.05\right)$, inferring the lack of relationship between phylogeny and the geographic distribution of haplotypes.

The one-level AMOVA showed weak but significant genetic differentiation based on nucleotide divergence $\left(\Phi_{\mathrm{ST}}=0.022, \mathrm{df}=335, P=0.031\right)$. The general trend of 
partitioning genetic variation among populations was not confirmed based on haplotype frequency $\left(F_{\mathrm{ST}}=\right.$ $0.016, \mathrm{df}=335, P=0.058$ ). Pairwise comparisons of genetic differentiation, estimated from genetic divergence and haplotype frequency, are presented in Table V. Population genetic structure was investigated grouping populations under different biogeographic hypotheses (Table VI). Analysis of molecular variance (two-level AMOVA) showed significant population structure along the West-East geographic gradient, depicting a weak but significant difference between the Atlantic and Mediterranean based on nucleotide divergence $\left(\Phi_{C T}=0.049 ; P<0.05\right)$. Although a significant result was also noted when considering three groups (Atlantic vs. Western Mediterranean vs. Eastern Mediterranean), partitioning the genetic variance among Atlantic and Mediterranean Basins yielded the highest $\Phi_{C T}$ and explained most of the population genetic structure of Pachygrapsus marmoratus. The Mantel test revealed no significant correlation between genetic and geographic distances $(r=-0.069$, $P=0.741$ ), suggesting a lack of isolation by distance.

\section{Discussion}

The present investigation mainly focuses on the population genetic structure of the intertidal marbled crab Pachygrapsus marmoratus across the Siculo-Tunisian Strait, investigating mtDNA and nuclear variation among eight North African populations. Analyses of mtDNA and microsatellite loci showed contrasting patterns of population differentiation, but both markers revealed no significant genetic structure across the Siculo-Tunisian Strait.

Overall, our mtDNA results showed a relatively homogeneous mtDNA haplotype composition among populations of the African Mediterranean coast belonging to distinct basins. The geographic distribution of haplotypes also showed that the most common haplotype (haplotype 1, Figure 4a) was present in all populations in high frequencies. This suggests the existence of high gene flow connecting populations separated by hundreds of kilometres (such as the Algerian population of Annaba and the Libyan population of Tajura) and maintaining the observed genetic homogeneity. This finding is in contrast with the genetic structure previously recorded with the same marker in other decapod species, such as the caramote prawn Penaeus kerathurus Forskål, 1775 (see Zitari-Chatti et al. 2009) and the green crab Carcinus aestuarii Nardo, 1847 (see Deli et al. 2015b) across the investigated region. This suggests that the lack of mtDNA-based genetic structure in Pachygrapsus marmoratus could be linked to incomplete lineage sorting, owing to a slow mtDNA mutation rate in this species. Although the Cox1 gene has been shown to be variable enough in different decapod species (Fratini \& Vannini 2002; Roman \& Palumbi 2004; Darling et al. 2008; Silva et al. 2010; Laurenzano et al. 2014), it also failed to reveal genetic structuring in other brachyuran species, like the blue crab Callinectes bellicosus Stimpson, 1859 (see Pfeiler et al. 2005) or the fiddler crab Uca (Leptuca) uruguayensis Nobili, 1901 (see Laurenzano et al. 2013). The absence of genetic structure could also indicate the possible signature of historical mixing events that took place in the investigated region (i.e. through a possible bottleneck during the glaciation periods in the Mediterranean).

The BSP estimate of the effective population size fluctuations of the North African metapopulation showed a gradual increase over time, characteristic of a population in a phase of demographic recovery following an historical bottleneck (Hoffman et al. 2011). However, we should caution with the fact that the actual effective population size does not appear to be much greater than in the past. This might be due to the limited number of analysed specimens (less than 100 ), which can prevent the capture of the full extent of a population expansion (Grant 2015). The obtained BSP result is concordant with the ragged unimodal mismatch distribution and the star-like haplotype network. Furthermore, the estimated time of expansion under both demographic (0.837 million years ago) and spatial (0.788 million years ago) expansion models coincides well with Pleistocene glaciation periods, and seems to indicate that the North African metapopulation of $P$. marmoratus might have experienced rapid historical population growth from an ancestral population with a small effective population size in the Mid-Pleistocene. During this period, the Mediterranean Sea experienced strong climatic changes and sea level fluctuations, supposedly affecting the genetic population structure of many marine species (for a review see Hewitt 2000 and Patarnello et al. 2007).

Despite the lack of differentiated geographic groups within P. marmoratus, both one-level AMOVA and Fisher exact tests, based on microsatellite data, showed significant partitioning of genetic variation among North African populations. This result contrasts clearly with that inferred from mtDNA analyses of the same populations. However, the recorded population subdivision was not in accordance with geographic boundaries nor correlated with geographic distances, as revealed by the Mantel test. Accordingly, the genetic separation among populations could be attributed to the small effective size contributing to the next 
Table V. Pairwise comparisons of genetic differentiation estimated from genetic divergence ( $\Phi_{\mathrm{ST}}$, below the diagonal) and haplotype frequency $\left(F_{\mathrm{ST}}\right.$, above the diagonal), based on the mtDNA Cox1 gene. Values with $P<0.05$ are reported in bold (significance levels calculated from 10,000 permutations).

\begin{tabular}{|c|c|c|c|c|c|c|c|c|c|c|c|c|c|c|c|c|c|c|c|c|c|c|c|c|}
\hline & \multicolumn{2}{|c|}{ Atlantic } & \multicolumn{16}{|c|}{ Western Mediterranean } & \multicolumn{6}{|c|}{ Eastern Mediterranean } \\
\hline & MAT & SSB & CAI & VAL & TRG & SFL & CAL & $\mathrm{RCH}$ & PER & GIG & MTC & GAE & FUS & MES & ANN & $\mathrm{BIZ}$ & KOR & CAP & SHL & SFX & ZRZ & TAJ & CRT & BLB \\
\hline ИАТ & * & 0.101 & -0.01 & 0.037 & 0.00 & -0.01 & -0.01 & -0.00 & 0.03 & 0.072 & 0.004 & 0.015 & -0.01 & 0.029 & 0.027 & -0.0 & 0.131 & -0.04 & 0.002 & -0.0 & 0.010 & -0.00 & 0.017 & 0.013 \\
\hline SSB & 0.051 & * & 0.031 & 0.003 & 0.18 & 0.110 & 0.086 & 0.176 & 0.05 & 0.306 & 0.183 & 0.168 & 0.097 & 0.230 & 0.229 & 0.15 & 0.418 & 0.136 & 0.085 & 0.26 & 0.170 & 0.088 & 0.040 & 0.115 \\
\hline CAI & -0.016 & .003 & * & -0.02 & 0.01 & -0.02 & -0.03 & 0.011 & -0.0 & 0.074 & 0.014 & 0.006 & -0.03 & 0.041 & 0.033 & -0.0 & 0.164 & -0.02 & -0.05 & 0.03 & 0.007 & -0.04 & -0.03 & -0.01 \\
\hline VAL & 0.028 & 0.011 & -0.02 & * & 0.07 & 0.02 & -0.00 & 0.059 & -0.0 & 0.133 & 0.078 & 0.042 & -0.00 & 0.099 & 0.090 & 0.03 & 0.254 & 0.038 & -0.02 & 0.13 & 0.060 & -0.02 & -0.03 & 0.011 \\
\hline TRG & 0.045 & 0.195 & 0.063 & 0.07 & * & -0.00 & -0.01 & -0.02 & 0.04 & -0.03 & -0.01 & -0.03 & -0.01 & -0.04 & -0.01 & -0.0 & 0.012 & -0.02 & -0.00 & -0.0 & -0.00 & -0.01 & 0.028 & -0.01 \\
\hline $\mathrm{FL}$ & 0.001 & 101 & 0.00 & -0.00 & 0.00 & $*$ & -0.02 & -0.04 & 0.00 & 0.015 & (20 & -0.01 & -0.02 & 0.005 & -003 & -0.0 & 5 & -0.03 & & -0.0 & -0 . & & -0.01 & -0.01 \\
\hline CAL & 0.017 & 0.131 & 0.011 & 0.015 & -0.03 & -0.03 & * & -0.00 & -0.0 & 0.034 & 0.005 & -0.01 & -0.04 & 0.013 & 0.012 & -0.0 & 0.107 & -0.02 & -0.04 & 0.01 & 0.001 & -0.04 & -0.02 & -0.02 \\
\hline $\mathrm{RCH}$ & 0.063 & 0.208 & 0.076 & 0.061 & -0.01 & -0.03 & -0.00 & s & 0.04 & -0.02 & -0.01 & -0.02 & -0.01 & -0.01 & -0.05 & -0.0 & 0.034 & -0.03 & -0.01 & -0.0 & -0.02 & -0.01 & 0.009 & -0.02 \\
\hline PER & 0.016 & 0.100 & -0.02 & -0.02 & 0.00 & -0.03 & -0.03 & 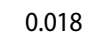 & . & 0.06 & & 0.013 & -0.03 & 0.056 & & 0.0 & 0.209 & 0.027 & -0.05 & 0.10 & 0.060 & -0.02 & -0.04 & -0.01 \\
\hline GIG & 0.170 & 0.411 & 0.205 & 0.196 & -0.02 & 0.04 & 0.03 & -0.02 & 0.11 & * & 0.010 & -0.03 & -0.00 & -0.05 & -0.01 & 0.04 & -0.00 & 0.023 & 0.016 & -0.0 & 0.022 & 0.015 & 0.058 & -0.00 \\
\hline MTC & 0.009 & 0.116 & 0.003 & 0.029 & -0.02 & -0.02 & -0.03 & -0.00 & -0.0 & 0.02 & . & -0.01 & -0.00 & -0.01 & -0.01 & -0.0 & 0.036 & -0.03 & 00 & -0.0 & -0.02 & -0.01 & 0.020 & 0.000 \\
\hline $\mathrm{GAE}$ & 0.016 & 0.158 & 0.026 & 0.047 & -0.03 & -0.02 & -0.03 & -0.00 & -0.0 & 0.000 & 0.03 & * & -0.03 & -0.03 & -0.02 & -0.0 & 0.041 & -0.02 & -0.03 & -0.0 & -0.01 & -0.03 & -0.00 & -0.03 \\
\hline FUS & -0.013 & 0.137 & 0.004 & 0.031 & -0.03 & -0.03 & -0.04 & -0.00 & -0.0 & 0.029 & -0.04 & -0.04 & * & -0.01 & 0.010 & -0.0 & 0.113 & -0.02 & -0.05 & 0.01 & 0.000 & -0.05 & -0.04 & -0.03 \\
\hline MES & 0.077 & 0.249 & 0.098 & & -0.03 & -0.00 & -0.00 & -0.02 & 0.03 & -0.05 & -0.0 & -0.03 & -0.02 & . & -0.00 & 0.01 & & & & -0.0 & & & 0.040 & -0.01 \\
\hline ANN & 0.109 & 0.315 & 0.143 & 42 & -0.01 & 0.00 & 0. & -0.05 & 0.08 & -0.06 & 10 & -0.01 & 0.010 & -0.03 & * & -0.0 & 0.027 & -0.02 & 0.008 & -0.0 & -0.03 & -0.00 & 0.025 & 0.003 \\
\hline $\mathrm{BIZ}$ & -0.00 & 0.060 & -0.01 & -0.01 & 0.02 & -0.02 & -0.01 & 0.013 & -0.0 & 0.098 & -0.01 & -0.01 & -0.01 & 0.040 & 0.044 & * & 0.067 & -0.04 & -0.01 & -0.0 & -0.03 & -0.03 & 0.008 & -0.00 \\
\hline KOR & 0.149 & 0.378 & 0.207 & 0.244 & 0.02 & 0.09 & & 0.049 & 0.16 & 0.003 & & 0.040 & 0.060 & 0.014 & -0.01 & 0.0 & $*$ & 0.070 & 0.122 & -0.0 & 0.059 & 0.103 & 0.183 & 0.091 \\
\hline CAP & -0.02 & 0.138 & -0.00 & 0.040 & -0.02 & -0.03 & -0 . & -0.00 & -0.0 & 0.039 & -0.04 & -0.04 & -0.05 & -0.01 & -0.00 & -0.0 & 0.039 & * & -0.03 & -0.0 & -0.01 & -0.03 & 0.004 & -0.01 \\
\hline SHL & 0.013 & 0.046 & -0.04 & -0.04 & 0.03 & -0.02 & -0.02 & 0.033 & -0.0 & 0.143 & -0.02 & 0.010 & -0.00 & 0.064 & 0.095 & -0.0 & 0.171 & -0.00 & * & 0.03 & 0.002 & -0.05 & -0.04 & -0.04 \\
\hline SFX & 0.065 & 0.347 & 0.141 & 0.183 & -0.03 & 0.03 & 0.03 & 0.00 & 0.10 & -0.00 & -0.00 & -0.02 & -0.01 & -0.03 & -0.03 & 0.06 & -0.04 & -0.02 & 0.126 & $*$ & -0.01 & 0.015 & 0.077 & 0.015 \\
\hline ZRZ & 0.005 & 0.146 & 0.018 & 0.040 & -0.03 & -0.04 & -0.03 & -0.03 & -0.0 & -0.00 & -0.03 & -0.04 & -0.05 & -0.04 & -0.03 & -0.0 & 0.024 & -0.04 & 0.003 & -0.0 & * & -0.03 & 0.007 & -0.00 \\
\hline TAJ & -0.036 & 0.062 & -0.03 & -0.01 & -0.00 & -0.03 & -0.03 & 0.015 & -0.0 & 0.088 & -0.04 & -0.03 & -0.05 & 0.009 & 0.049 & -0.0 & 0.077 & -0.04 & -0.03 & 0.03 & -0.04 & * & -0.05 & -0.04 \\
\hline CRT & 0.016 & 0.067 & -0.02 & -0.03 & 0.01 & -0.04 & -0.03 & 0.007 & -0.0 & 0.097 & -0.02 & -0.00 & -0.02 & 0.030 & 0.068 & -0.0 & 0.162 & -0.00 & -0.04 & 0.10 & -0.01 & -0.04 & $*$ & -0.02 \\
\hline BLB & 0.019 & 0.075 & -0.01 & -0.02 & 0.01 & -0.04 & -0.02 & -0.00 & -0.0 & 0.091 & -0.01 & -0.00 & -0.01 & 0.028 & 0.058 & -0.0 & 0.159 & -0.00 & -0.03 & 0.09 & -0.02 & -0.03 & -0.05 & . \\
\hline
\end{tabular}

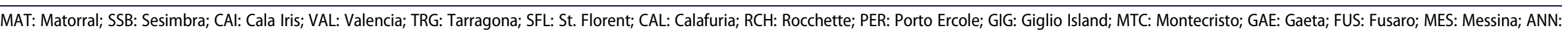
Annaba; BIZ: Bizerte; KOR: Korbos; CAP: Cap Bon; SHL: Sahel; SFX: Sfax; ZRZ: Zarzis; TAJ: Tajura; CRT: Crotone; BLB: Beldibi. 
Table VI. Two-level AMOVA, assessing population genetic structure of Pachygrapsus marmoratus under different biogeographic hypotheses, based on the mtDNA Cox1 gene.

\begin{tabular}{lcc}
\hline Grouping & $\begin{array}{c}\text { Nucleotide divergence } \\
\text { (Tajima and Nei distance) }\end{array}$ & $\begin{array}{c}\text { Haplotype } \\
\text { frequency }\end{array}$ \\
\hline Across the Gibraltar Strait: & $\boldsymbol{\Phi}_{\mathrm{SC}}=\mathbf{0 . 0 1 2} *$ & $F_{\mathrm{SC}}=0.009 \mathrm{~ns}$ \\
Atlantic vs. Mediterranean & $\boldsymbol{\Phi}_{\mathrm{ST}}=\mathbf{0 . 0 6 0} *$ & $F_{\mathrm{ST}}=0.042 \mathrm{~ns}$ \\
& $\boldsymbol{\Phi}_{\mathrm{CT}}=\mathbf{0 . 0 4 9} *$ & $F_{\mathrm{CT}}=0.033 \mathrm{~ns}$ \\
Across the Gibraltar and & & \\
Siculo-Tunisian Straits: & $\boldsymbol{\Phi}_{\mathrm{SC}}=0.012 \mathrm{~ns}$ & $F_{\mathrm{SC}}=0.010 \mathrm{~ns}$ \\
Atlantic vs. Western & $\boldsymbol{\Phi}_{\mathrm{ST}}=\mathbf{0 . 0 3 1}{ }^{*}$ & $F_{\mathrm{ST}}=0.021 \mathrm{~ns}$ \\
Mediterranean vs. Eastern & $\boldsymbol{\Phi}_{\mathrm{CT}}=\mathbf{0 . 0 1 8} *$ & $F_{\mathrm{CT}}=0.010 \mathrm{~ns}$ \\
Mediterranean & & \\
\hline
\end{tabular}

Populations and grouping: Atlantic: Matorral and Sesimbra; Mediterranean: Cala Iris, Valencia, Tarragona, St. Florent, Calafuria, Rocchette, Porto Ercole, Giglio Island, Montecristo, Gaeta, Fusaro, Messina, Annaba, Bizerte, Korbos, Cap Bon, Sahel, Sfax, Zarzis, Tajura and Beldibi; Western Mediterranean: Cala Iris, Valencia, Tarragona, St. Florent, Calafuria, Rocchette, Porto Ercole, Giglio Island, Montecristo, Gaeta, Fusaro, Messina, Annaba, Bizerte, Korbos, Cap Bon; Eastern Mediterranean: Sahel, Sfax, Zarzis, Tajura, Crotone and Beldibi. *: $P<0.05 ; n s$, non-significant difference $(P>0.05)$.

generation or a 'sweepstakes effect' (Hedgecock 1994). This view may be supported by the outcomes of the BAPS and PCA analyses of genotypes, showing remarkable genetic separation of certain populations, i.e. Bizerte, Korbos and Tajura. This pattern of separation, which does not seem to be associated with a clear geographic gradient, may rather follow a 'chaotic genetic patchiness' in the composition of recruits (Christie et al. 2010), as has been suggested previously for Portuguese (Silva et al. 2009b) and Italian (Fratini et al. 2011, 2013) populations of $P$. marmoratus.

This study provides evidence for the absence of a significant genetic structure across the Siculo-Tunisian Strait, as inferred from mtDNA and nuclear microsatellite loci analyses. The Siculo-Tunisian Strait is considered as a well-documented genetic boundary between African Mediterranean populations of many marine species of fishes (Bahri-Sfar et al. 2000; Mejri et al. 2009; Kaouèche et al. 2011), molluscs (Gharbi et al. 2011) and shrimps (Zitari-Chatti et al. 2009), but apparently does not seem to interrupt the connectivity among African populations of $P$. marmoratus from the Western and Eastern Mediterranean Basins. The lack of genetic structure could be explained by the passive dispersal of planktonic larvae, which could limit the formation of population substructure (Lessios et al. 2003; Waters \& Roy 2004). Pachygrapsus marmoratus planktonic larvae seem to have a high dispersive capacity, characteristic of many marine invertebrates. Zoeae spend around one month offshore, going through at least six development stages (Cuesta \& Rodríguez 2000). Movement of juveniles and adults of $P$. marmoratus is not expected to homogenize populations. Instead, larval dispersal during a long planktonic phase could promote the connectivity of the local adult populations in accordance with hydrographic patterns. In theory, drifting P. marmoratus larvae can reach very distant locations along the North-African littoral. The latter is characterized by a unidirectional surface current, called the Algerian Current, originating from the Atlantic, moving eastwards along the North African coast and flowing into the Eastern Mediterranean Basin (Béranger et al. 2004, Figure 1). This marine current along the continuous African Mediterranean coast could have enhanced genetic homogeneity of the studied populations according to a linear stepping stone model. Indeed, this model is common in continuously distributed species, like $P$. marmoratus, in which homogenization of distant populations is maintained by gene flow through the exchange of individuals between adjacent or nearby populations (Kimura \& Weiss 1964; Slatkin \& Maddison 1990).

Analysis of a shorter fragment of the mitochondrial Cox 1 marker across a broader geographic scale, covering almost the entire distribution range of this species, showed significant genetic differentiation among populations, as revealed by the one-level AMOVA. Based on this enlarged dataset, the results of the structured AMOVA analysis hint at the existence of significant genetic structure along a West-East geographic gradient, depicting weak but significant differentiation between Atlantic and Mediterranean populations. These results are the first to reflect such patterns of genetic structure for $P$. marmoratus. Previous mtDNA phylogeographic studies of the same species across different geographic scales failed to detect population differentiation and suggested the existence of overall genetic homogeneity (Fratini et al. 2011; Deli et al. 2015a). However, the genetic heterogeneity observed in this study is not due to isolation by distance. Indeed, the most significant pairwise differences were not between geographically extreme populations. The great diversity of habitats and, therefore, selective forces within both Mediterranean basins and the Atlantic could contribute to the onset of enclosures or dispatched isolates (genetic separation of specific populations that is not linked to any geographic gradient). Furthermore, the potentially random distribution of larvae according to oceanographic currents would be critical in the development of such isolates (Johnson \& Black 2006). Accordingly, we can attribute the genetic differentiation among Atlantic and Mediterranean populations to the impact of various oceanographic circulation patterns in the area of the Gibraltar Strait, resulting in a barrier to gene flow (Quesada et al. 1995). The Almeria-Oran Oceanographic Front 
constitutes an important barrier for many marine species with planktonic larval stages (Patarnello et al. 2007). Based solely on the analysis of mitochondrial DNA and in the absence of data from nuclear markers from this area, the exact barrier cannot be determined. It should be noted that although the mtDNA-derived estimates do represent female dispersal, it can be seen to be representative of overall dispersal, because sex-biased dispersal among planktonic larvae is not expected (Barber et al. 2006). It should be mentioned that the lack of a relationship between phylogeography and the geographic distribution of haplotypes, identified by the parsimony network and supported statistically by the program PERMUT, could be attributed to the fact that the Cox 1 mitochondrial marker can retain the ancestral polymorphisms of P. marmoratus due to its low mutation rate.

As far as can be inferred from our results, mitochondrial and nuclear DNA patterns of population structure across part of the African Mediterranean coasts are in accordance with those previously reported for geographically close European populations (Fratini et al. 2008, 2013; Silva et al. 2009b). Mitochondrial DNA homogeneity vs. nuclear DNA patchiness, detected so far in different examined geographic regions (Fratini et al. 2008, 2011, 2013; Silva et al. 2009b; Deli et al. 2015a), probably result from the involvement of a complex series of abiotic and biotic factors in determining genetic structure, of which the origin and effect should be determined in future investigations. Furthermore, the observed weak mtDNA heterogeneity across the Gibraltar Strait cannot be considered a conclusive result, as more populations from the Atlantic and Mediterranean (including the Eastern Basin and Black Sea) need to be analysed in order to verify this pattern and to obtain a complete overview of phylogeographic structure of $P$. marmoratus across its distribution range. This would help to shed more light on inter-population and inter-regional differentiation and allow understanding of the evolutionary history of this species.

\section{Acknowledgements}

We are grateful to everybody who assisted in this work. Specifically, we thank our colleagues from Algeria (Lamia Boudechiche) and Libya (Daou Haddoud) for their help with crab sampling and Andreas Trindl at the University of Regensburg for help with the microsatellites. We would also like to thank two anonymous reviewers for their helpful and interesting comments and suggestions to improve the manuscript quality.

\section{Disclosure statement}

No potential conflict of interest was reported by the authors.

\section{Funding}

This work was co-funded by the University of Monastir (Tunisia) and the Institute of Zoology (Chair: Prof. Jürgen Heinze) at the University of Regensburg (Germany).

\section{References}

Arnaud-Haond S, Diaz Almela E, Teixeira S. 2007. Vicariance patterns in the Mediterranean Sea: East-West cleavage and low dispersal in the endemic seagrass (Posidonia oceanica). Journal of Biogeography 14:963-76. doi:10.1111/j. 1365-2699.2006.01671.x

Astraldi M, Balopoulos S, Candela J, Font J, Gacic M, Gasparini $\mathrm{GP}$, et al. 1999. The role of straits and channels in understanding the characteristics of Mediterranean circulation. Progress in Oceanography 44:65-108. doi:10.1016/S00796611(99)00021-X

Bahri-Sfar L, Lemaire C, Ben Hassine OK, Bonhomme F. 2000. Fragmentation of sea bass populations in the western and eastern Mediterranean as revealed by microsatellite polymorphism. Proceedings of the Royal Society B 267:92935. doi:10.1098/rspb.2000.1092

Barber PH, Erdmann MV, Palumbi SR. 2006. Comparative phylogeography of three codistributed stomatopods: origins and timing of regional lineage diversification in the coral triangle. Evolution 60:1825-39. doi:10.1111/j.0014-3820. 2006.tb00526.x

Béranger K, Mortier L, Gasparini GP, Gervasio L, Astraldi M, Crépon M. 2004. The dynamics of the Sicily Strait: a comprehensive study from observations and models. Deep Sea Research II 51:411-40. doi:10.1016/j.dsr2.2003.08.004

Borsa P, Blanquer A, Berrebi P. 1997. Genetic structure of the flounders Platichthys flesus and $P$. stellatus at different geographic scales. Marine Biology 129:233-46. doi:10.1007/ s002270050164

Brookfield JFY. 1996. A simple new method for estimating null allele frequency from heterozygote deficiency. Molecular Ecology 5:453-55. doi:10.1046/j.1365-294X.1996.00098.x

Cannicci S, Paula J, Vannini M. 1999. Activity pattern and spatial strategy in Pachygrapsus marmoratus (Decapoda: Grapsidae) from Mediterranean and Atlantic shores. Marine Biology 133:429-35. doi:10.1007/s002270050481

Cannicci S, Gomei M, Boddi B, Vannini M. 2002. Feeding habits and natural diet of the intertidal crab (Pachygrapsus marmoratus): opportunistic browser or selective feeder? Estuarine, Coastal and Shelf Science 54:983-1001. doi:10.1006/ecss.2001.0869

Chapuis MP, Estoup A. 2007. Microsatellite null alleles and estimation of population differentiation. Molecular Biology and Evolution 24:621-31. doi:10.1093/molbev/ msl191

Christie MR, Johnson DW, Stalling CD, Hixon MA. 2010. Selfrecruitment and sweepstakes reproduction amid extensive gene flow in a coral-reef fish. Molecular Ecology 19:104257. doi:10.1111/j.1365-294X.2010.04524.x 
Clement M, Posada D, Crandall K. 2000. TCS: a computer program to estimate gene genealogies. Molecular Ecology 9:1657-60. doi:10.1046/j.1365-294x.2000.01020.x

Corander J, Waldmann P, Sillanpaa MJ. 2003. Bayesian analysis of genetic differentiation between populations. Genetics 163:367-74.

Corander J, Marttinen P, Mäntyniemi S. 2005. Bayesian identification of stock mixtures from molecular marker data. Fishery Bulletin 104:550-58.

Cornuet JM, Luikart G. 1996. Description and power analysis of two tests for detecting recent population bottlenecks from allele frequency data. Genetics 144:2001-14.

Cuesta JA, Rodríguez A. 2000. Zoeal stages of the intertidal crab (Pachygrapsus marmoratus (Fabricius, 1787)) (Brachyura, Grapsidae) reared in the laboratory. Hydrobiologia 436:119-30. doi:10.1023/A:1026576614590

Cuesta JA, Guerao G, Schubart CD, Anger K. 2011. Morphology and growth of the larval stages of Geograpsus lividus (Crustacea, Brachyura), with the descriptions of new larval characters for the Grapsidae and an undescribed setation pattern in extended developments. Acta Zoologica 92:225-40. doi:10.1111/j.1463-6395.2010. 00482.x

Darling JA, Bagley JM, Roman J, Tepolt CK, Geller JB. 2008. Genetic patterns across multiple introductions of the globally invasive crab genus Carcinus. Molecular Ecology 17:4992-5007. doi:10.1111/j.1365-294X.2008.03978.x

Deli T, Bahles H, Said K, Chatti N. 2015a. Patterns of genetic and morphometric diversity in the marbled crab (Pachygrapsus marmoratus, Brachyura, Grapsidae) populations across the Tunisian coast. Acta Oceanologica Sinica 34(6):49-58. doi:10.1007/s13131-015-0687-7

Deli T, Said K, Chatti N. 2015b. Genetic differentiation among populations of the green crab (Carcinus aestuarii) (Brachyura, Carcinidae) from the Eastern and Western Mediterranean coasts of Tunisia. Acta Zoologica Bulgarica 67(3):327-35.

Di Rienzo A, Peterson AC, Garza JC, Valdes AM, Slatkin M, Freimer NB. 1994. Mutational processes of simple sequence repeat loci in human populations. Proceedings of the National Academy of Sciences 91:3166-70. doi:10. 1073/pnas.91.8.3166

Drummond AJ, Rambaut A, Shapiro B, Pybus OG. 2005. Bayesian coalescent inference of past population dynamics from molecular sequences. Molecular Biology and Evolution 22:1185-92. doi:10.1093/molbev/msi103

Drummond AJ, Suchard MA, Xie D, Rambaut A. 2012. Bayesian phylogenetics with BEAUti and the BEAST 1.7. Molecular Biology and Evolution 29:1969-73. doi:10.1093/molbev/ mss075

Excoffier L. 2004. Patterns of DNA sequence diversity and genetic structure after a range expansion: lessons from the infinite-island model. Molecular Ecology 13:853-64. doi:10.1046/j.1365-294X.2003.02004.x

Excoffier L, Smouse PE, Quattro JM. 1992. Analysis of molecular variance inferred from metric distances among DNA haplotypes: application to human mitochondrial DNA restriction data. Genetics 131:479-91.

Excoffier L, Laval G, Schneider S. 2005. Arlequin ver. 3.0: an integrated software package for population genetics data analysis. Evolutionary Bioinformatics Online 1:47-50.
Ferreira Silva AC, Brazão S, Hawkins SJ, Thompson RC, Boaventura DM. 2009. Abundance, population structure and claw morphology of the semi-terrestrial crab Pachygrapsus marmoratus (Fabricius, 1787) on shores of differing wave exposure. Marine Biology 156:2591-99. doi:10.1007/s00227-009-1283-1

Fisher RA. 1935. The logic of inductive inference (with discussion). Journal of the Royal Statistical Society 98:39-82. doi: $10.2307 / 2342435$

Flores AAV, Paula J. 2002. Sexual maturity, larval release and reproductive output of two brachyuran crabs from a rocky intertidal area in central Portugal. Invertebrate Reproduction and Development 42(1):21-34. doi:10.1080/ 07924259.2002 .9652506

Fratini S, Vannini M. 2002. Genetic differentiation in the swimming crab Scylla serrata (Decapoda: Portunidae) within the Indian Ocean. Journal of Experimental Marine Biology and Ecology 272:103-16. doi:10.1016/S0022-0981(02)00052-7

Fratini S, Ragionieri L, Papetti C, Rorandelli R, Barbaresi S, Zane L. 2006. Isolation and characterization of microsatellites in Pachygrapsus marmoratus (Grapsidae; Decapoda; Brachyura). Molecular Ecology Notes 6:179-81. doi:10. 1111/j.1471-8286.2005.01184.x

Fratini S, Zane L, Ragionieri L, Vannini M, Cannicci S. 2008. Relationship between heavy metal accumulation and genetic variability decrease in the intertidal crab Pachygrapsus marmoratus (Decapoda; Grapsidae). Estuarine, Coastal and Shelf Science 79(4):679-86. doi:10. 1016/j.ecss.2008.06.009

Fratini S, Schubart CD, Ragionieri L. 2011. Population genetics in the rocky shore crab (Pachygrapsus marmoratus) from the western Mediterranean and eastern Atlantic: complementary results from mtDNA and microsatellites at different geographic scales. In: Held C, Koenemann S, Schubart CD, editors. Crustacean Issues 19: Phylogeography and Population Genetics in Crustacea. Boca Raton, FL: CRC Press, p 191-213.

Fratini S, Ragionieri L, Cutuli G, Vannini M, Cannicci S. 2013. Pattern of genetic isolation in the crab Pachygrapsus marmoratus within the Tuscan Archipelago (Mediterranean Sea). Marine Ecology Progress Series 478:173-83. doi:10. 3354/meps 10247

Fu YX. 1997. Statistical tests of neutrality of mutations against population growth, hitchhiking and background selection. Genetics 147:915-25.

Gharbi A, Zitari-Chatti R, Van Womhoudt A, Dhraief MN, Denis F, Said K, Chatti N. 2011. Allozyme variation and population genetic structure in the carpet shell clam (Ruditapes decussatus) across the Siculo-Tunisian Strait. Biochemical Genetics 49:788-805. doi:10.1007/s10528-011-9450-8

Goudet J. 1995. FSTAT (version 1.2): a computer program to calculate F-statistics. Journal of Heredity 86:485-86. Computer program.

Goudet J. 1999. PCA-GEN for Windows. Version 1.2. Computer program.

Grant WS. 2015. Problems and cautions with sequence mismatch analysis and Bayesian Skyline Plots to infer historical demography. Journal of Heredity 106(4):333-46. doi:10. 1093/jhered/esv020

Hall TA. 1999. BioEdit: a user-friendly biological sequence alignment editor and analysis program for Windows 95 / 98 / NT. Nucleic Acids Symposium Series 41:95-98. 
Harpending HC. 1994. Signature of ancient population growth in a low-resolution mitochondrial DNA mismatch distribution. Human Biology 66(4):591-600.

Hedgecock D. 1994. Does variance in reproductive success limit effective population size of marine organisms? In: Beaumont AR, editor. Genetics and Evolution of Aquatic Organisms. London: Chapman and Hall, p 122-35.

Hewitt GM. 2000. The genetic legacy of the Quaternary ice ages. Nature 405:907-13. doi:10.1038/35016000

Hoffman JI, Grant SM, Forcada J, Phillips CD. 2011. Bayesian inference of a historical bottleneck in a heavily exploited marine mammal. Molecular Ecology 20(19):3989-4008. doi:10.1111/j.1365-294X.2011.05248.x

Ingle RW. 1980. British Crabs. British Museum (Natural History). London: Oxford University Press. 222 pages.

Ingle RW, Clark PF. 2006. First reported occurrences of the marbled crab, Pachygrapsus marmoratus (Crustacea: Brachyura: Grapsoidea) in southern coastal waters of the British Isles. Marine Biodiversity Records 1:e26. 5 pages. doi:10.1017/S1755267206002454.

Johnson MS, Black R. 2006. Islands increase genetic subdivision and disrupt patterns of connectivity of intertidal snails in a complex archipelago. Evolution 60:2498-506. doi:10.1111/j.0014-3820.2006.tb01885.x

Kaouèche $M$, Bahri-Sfar L, González-Wangüemert $M$, PérezRuzafa Á, Ben Hassine OK. 2011. Allozyme and mtDNA variation of white seabream (Diplodus sargus) populations in a transition area between western and eastern Mediterranean basins (Siculo-Tunisian Strait). African Journal of Marine Science 33(1):79-90. doi:10.2989/ $1814232 X .2011 .572342$

Kimura M, Weiss GH. 1964. The stepping stone model of population structure and the decrease of genetic correlation with distance. Genetics 49:561-76.

Latch EK, Dharmarajan G, Glaubitz JC, Rhodes OE. 2006. Relative performance of Bayesian clustering software for inferring population substructure and individual assignment at low levels of population differentiation. Conservation Genetics 7:295-302. doi:10.1007/s10592005-9098-1

Laurenzano C, Farias NE, Schubart CD. 2013. Mitochondrial genetic structure of two populations of Uca urugayensis fails to reveal an impact of the Rio de la Plata on gene flow. Nauplius 20:15-25. doi:10.1590/S010464972012000100003

Laurenzano C, Mantelatto FL, Schubart CD. 2014. South American homogeneity versus Caribbean heterogeneity: population genetic structure of the western Atlantic fiddler crab Uca rapax (Brachyura, Ocypodidae). Journal of Experimental Marine Biology and Ecology 449:22-27. doi:10.1016/j.jembe.2013.08.007

Lessios HA, Kane J, Robertson DR. 2003. Phylogeography of the pantropical sea urchin Tripneustes: contrasting patterns of population structure between oceans. Evolution 57:2026-36. doi:10.1111/j.0014-3820.2003.tb00382.x

Li WH. 1977. Distribution of nucleotide differences between two randomly chosen cistrons in a finite population. Genetics 85:331-37.

Librado P, Rozas J. 2009. DnaSP v5: a software for comprehensive analysis of DNA polymorphism data. Bioinformatics 25:1451-2. doi:10.1093/bioinformatics/btp187
Luikart G, Cornuet JM. 1998. Empirical evaluation of a test for identifying recently bottlenecked populations from allele frequency data. Conservation Biology 12:228-37. doi:10. 1111/j.1523-1739.1998.96388.x

Luikart G, Allendorf FW, Cornuet JM, Sherwin WB. 1998. Distortion of allele frequency distributions provides a test for recent population bottlenecks. Journal of Heredity 89:238-47. doi:10.1093/jhered/89.3.238

Mantel N. 1967. The detection of disease clustering and a generalized regression approach. Cancer Research 27:209-20.

Mejri R, Lo Brutto S, Ben Hassine OK, Arculeo M. 2009. A study on Pomatoschistus tortonesei Miller 1968 (Perciformes, Gobiidae) reveals the Siculo-Tunisian Strait (STS) as a breakpoint to gene flow in the Mediterranean basin. Molecular Phylogenetics and Evolution 53:596-601. doi:10.1016/j.ympev.2009.04.018

Miller MP. 2005. Alleles in space: computer software for the joint analysis of interindividual spatial and genetic information. Journal of Heredity 96:722-724. doi:10.1093/ jhered/esi119

Nei M. 1987. Molecular Evolutionary Genetics. New York: Columbia University Press. 512 pages.

Nikula R, Vainola R. 2003. Phylogeography of Cerastoderma glaucum (Bivalvia: Cardiidae) across Europe: a major break in the Eastern Mediterranean. Marine Biology 143:339-50. doi:10.1007/s00227-003-1088-6

van Oosterhout C, Hutchinson WF, Wills DPM, Shipley P. 2004. MICRO-CHECKER: software for identifying and correcting genotyping errors in microsatellite data. Molecular Ecology Notes 4:535-38. doi:10.1111/j.1471-8286.2004.00684.x

Paetkau D, Calvert W, Stirling I, Strobeck C. 1995. Microsatellite analysis of population structure in Canadian polar bears. Molecular Ecology 4:347-54. doi:10.1111/j.1365-294X.1995.tb00227.x

Paetkau D, Slade R, Burden M, Estoup A. 2004. Genetic assignment methods for the direct, real-time estimation of migration rate: a simulation-based exploration of accuracy and power. Molecular Ecology 13:55-65. doi:10.1046/j. 1365-294X.2004.02008.x

Patarnello T, Volckaert FAM, Castilho R. 2007. Pillars of Hercules: is the Atlantic-Mediterranean transition a phylogeographical break? Molecular Ecology 16:4426-44. doi:10.1111/j.1365-294X.2007.03477.x

Petit RJ, Hampe A, Cheddadi R. 2005. Climate changes and tree phylogeography in the Mediterranean. Taxon 54:877-85. doi:10.2307/25065474

Pfeiler E, Hurtado LA, Knowles LL, Torre-Cossio J, BourillonMoreno L, Marquez-Farias JF, Montemayor-Lopez G. 2005. Population genetics of the swimming crab Callinectes bellicosus (Brachyura: Portunidae) from the eastern Pacific Ocean. Marine Biology 146:559-69. doi:10. 1007/s00227-004-1463-y

Piry S, Luikart G, Cornuet JM. 1999. BOTTLENECK: a computer program for detecting recent reductions in the effective population size using allele frequency data. Journal of Heredity 90:502-03. doi:10.1093/jhered/90.4.502

Piry S, Alapetite A, Cornuet JM, Paetkau D, Baudouin L, Estoup A. 2004. GENECLASS2: a software for genetic assignment and first-generation migrant detection. Journal of Heredity 95:536-39. doi:10.1093/jhered/esh074 
Pons O, Petit RJ. 1995. Estimation, variance and optimal sampling of gene diversity. Theoretical and Applied Genetics 90:462-70. doi:10.1007/BF00221991

Pons O, Petit RJ. 1996. Measuring and testing genetic differentiation with ordered versus unordered alleles. Genetics 144:1237-45.

Pritchard JK, Stephens M, Donnelly P. 2000. Inference of population structure using multilocus genotype data. Genetics 155:945-59.

Quesada H, Beynon CM, Skibinski DOF. 1995. A mitochondrial DNA discontinuity in the mussel Mytilus galloprovincialis Lmk: Pleistocene vicariance biogeography and secondary intergradations. Molecular Biology and Evolution 12:521-24.

Quignard JP. 1978. La Méditerranée creuset ichthyologique. Bolletino di Zoologica 45(Suppl. II):23-36. doi:10.1080/ 11250007809440264

Ragionieri L, Schubart CD. 2013. Population genetics, gene flow, and biogeographical boundaries of Carcinus aestuarii (Crustacea: Brachyura: Carcinidae) along the European Mediterranean coast. Biological Journal of the Linnean Society 109:771-90. doi:10.1111/bij.12099

Rambaut A, Drummond AJ. 2007. Tracer v 1.4.8. Institute of Evolutionary Biology, University of Edinburgh. Available from: http//beast.edu.ac.uk/Tracer. Computer program.

Ramos-Onsins SE, Rozas J. 2002. Statistical properties of new neutrality tests against population growth. Molecular Biology and Evolution 19:2092-100. doi:10.1093/ oxfordjournals.molbev.a004034

Rannala B, Mountain JL. 1997. Detecting immigration by using multilocus genotypes. Proceedings of the National Academy of Sciences 94:9197-201. doi:10.1073/pnas.94. 17.9197

Raymond M, Rousset F. 1995. GENEPOP (version 1.2): population genetics software for exact tests and ecumenicism. Journal of Heredity 86:248-49.

Rogers AR, Harpending H. 1992. Population growth makes waves in the distribution of pairwise genetic differences. Molecular Biology and Evolution 9:552-69.

Roman J, Palumbi SR. 2004. A global invader at home: population structure of the green crab, Carcinus maenas, in Europe. Molecular Ecology 13:2891-98. doi:10.1111/j. 1365-294X.2004.02255.x

Schubart CD. 2009. Mitochondrial DNA and decapod phylogenies: the importance of pseudogenes and primer optimization. In: Martin JW, Crandall KA, Felder DL, editors. Crustacean Issues 18: Decapod Crustacean Phylogenetics. Boca Raton, FL: Taylor and Francis / CRC Press, p 47-65.

Schubart CD, Diesel R, Hedges SB. 1998. Rapid evolution to terrestrial life in Jamaican crabs. Nature 393:363-65. doi:10.1038/30724

Silva IC, Paula J. 2008. Is there a better chela to use for geometric morphometric differentiation in brachyuran crabs? A case study using Pachygrapsus marmoratus and Carcinus maenas. Journal of the Marine Biological Association of the United Kingdom 88(5):941-53. doi:10. 1017/S0025315408001483

Silva IC, Hawkins SJ, Paula J. 2009a. A comparison of population differentiation in two shore crab species with contrasting distribution along the Portuguese coast, using two morphological methodologies. Marine and Freshwater Research 60(8):833-44. doi:10.1071/MF08215

Silva IC, Mesquita N, Schubart CD, Alves MJ, Paula J. 2009b. Genetic patchiness of the shore crab Pachygrapsus marmoratus along the Portuguese coast. Journal of Experimental Marine Biology and Ecology 378:50-57. doi:10.1016/j.jembe.2009.07.032

Silva IC, Mesquita N, Paula J. 2010. Genetic and morphological differentiation of the mangrove crab Perisesarma guttatum (Brachyura: Sesarmidae) along an East African latitudinal gradient. Biological Journal of the Linnean Society 99:2846. doi:10.1111/j.1095-8312.2009.01338.x

Simon C, Frati F, Beckenbach A, Crespi B, Liu H, Flook P. 1994. Evolution, weighting, and phylogenetic utility of mitochondrial gene sequences and a compilation of conserved polymerase chain reaction primers. Annals of the Entomological Society of America 87:651-701. doi:10. 1093/aesa/87.6.651

Slatkin M, Maddison WP. 1990. Detecting isolation by distance using phylogenies of genes. Genetics 126:249-60.

Stefanni S, Thorley JS. 2003. Mitochondrial DNA phylogeography reveals the existence of an evolutionarily significant unit of the sand goby Pomatoschistus minutus in the Adriatic (Eastern Mediterranean). Molecular Phylogenetics and Evolution 28:601-09. doi:10.1016/S1055-7903(03) 00054-X

Tajima F. 1983. Evolutionary relationships of DNA sequences in finite populations. Genetics 105:437-60.

Tajima F. 1989. The effect of change in population size on DNA polymorphism. Genetics 123:597-601.

Tajima F, Nei M. 1984. Estimation of evolutionary distance between nucleotide sequences. Molecular Biology and Evolution 1:269-85.

Tamura K, Peterson D, Peterson N, Stecher G, Nei M, Kumar S. 2011. MEGA5: molecular evolutionary genetics analysis using maximum likelihood, evolutionary distance, and maximum parsimony methods. Molecular Biology and Evolution 28:2731-39. doi:10.1093/molbev/msr121

Technelysium Pty Ltd. 2012. Chromas lite ver. 2.1.1. Available from: http://www.technelysium.com.au/chromas_lite.html. Computer program.

Waters JM, Roy MS. 2004. Phylogeography of a high-dispersal New Zealand sea-star: does upwelling block gene-flow? Molecular Ecology 13:2797-806. doi:10.1111/j.1365-294X. 2004.02282.x

Weir BS, Cockerham CC. 1984. Estimating F-statistics for the analysis of population structure. Evolution 38(6):1358-70. doi: $10.2307 / 2408641$

Zardoya R, Castilho R, Grande C, Favre-Krey L, Caetano S, Marcato $S$, et al. 2004. Differential population structuring of two closely related fish species, the mackerel (Scomber scombrus) and the chub mackerel (Scomber japonicus) in the Mediterranean Sea. Molecular Ecology 13:1785-98. doi:10.1111/j.1365-294X.2004.02198.x

Zitari-Chatti R, Chatti N, Fulgione D, Gaiazza I, Aprea G, Elouaer A, et al. 2009. Mitochondrial DNA variation in the caramote prawn Penaeus (Melicertus) kerathurus across a transition zone in the Mediterranean Sea. Genetica 136:439-47. doi:10.1007/s10709-008-9344-9 